\title{
Interactions of North Pacific Tropical, Midlatitude, and Polar Disturbances Resulting in Linked Extreme Weather Events over North America in October 2007임
}

\author{
LANCE F. Bosart And Benjamin J. MoOre \\ Department of Atmospheric and Environmental Sciences, University at Albany, State University of \\ New York, Albany, New York \\ JASON M. CORDEIRA \\ Department of Atmospheric Science and Chemistry, Plymouth State University, Plymouth, New Hampshire
}

\author{
Heather M. Archambault
}

NOAA/OAR Climate Program Office, Modeling, Analysis, Predictions and Projections Program, Silver Spring, Maryland

(Manuscript received 16 June 2016, in final form 2 December 2016)

\begin{abstract}
This study uses observations and model reanalyses to examine the multiscale processes associated with four high-impact extreme weather events (EWEs) over North America during late October 2007. The EWEs consisted of wind-driven wildfires in California, prolonged anomalous cold conditions in Mexico linked to two cold surges, heavy rainfall in the eastern United States, and severe flood-producing heavy rainfall in southern Mexico. The EWEs involved a pronounced large-scale flow reconfiguration across the North Pacific and North America in conjunction with the formation of a high-amplitude Rossby wave train. The flow reconfiguration involved perturbations to the North Pacific jet stream linked to polar, midlatitude, and tropical disturbances, including three tropopause-level polar disturbances originating over northeastern Asia, transient extratropical cyclones, a diabatic Rossby vortex, and western North Pacific Tropical Cyclone Kajiki. Eulerian and Lagrangian diagnostics indicate that ridge amplification within the wave train was enhanced in connection with latent heat release along warm conveyor belts rooted in the tropics and subtropics over the North Pacific. Two anticyclonic Rossby wave breaking events over North America established synoptic-scale conditions that supported the EWEs. The results highlight how the large- and synoptic-scale flow can evolve to facilitate multiple geographically separated but dynamically linked EWEs. Based on the results, it is posited that during autumn the North Pacific jet stream may be particularly conducive to large-scale flow amplification, possibly resulting in EWEs, in response to perturbations associated with tropical, midlatitude, and polar disturbances.
\end{abstract}

\section{Introduction}

During the final $\sim 10$ days of October 2007, four highimpact extreme weather events (EWEs) occurred over disparate regions of North America. These EWEs consisted of 1) destructive wind-driven wildfires in California, 2) drought-mitigating widespread heavy rainfall

Supplemental information related to this paper is available at the Journals Online website: http://dx.doi.org/10.1175/MWR-D16-0230.s1.

Corresponding author e-mail: Lance F. Bosart, lbosart@albany. edu over parts of the eastern United States, 3) anomalously cold conditions associated with two cold surges in Mexico, and 4) exceptionally heavy, flood-producing rainfall in the uplands of the southern Mexican states of Tabasco and Chiapas. Although geographically separate and appearing at first glance to occur in isolation, these EWEs were dynamically linked, each representing a distinctive consequence of a pronounced flow reconfiguration across the North Pacific and North America. The overarching objective of this study is to elucidate multiscale processes associated with this flow reconfiguration that culminated in the four linked EWEs.

The wildfires in Southern California, including the Los Angeles and San Diego metropolitan areas (Fig. 1a), 
(a) NASA Aqua satellite image, 22 Oct 2007
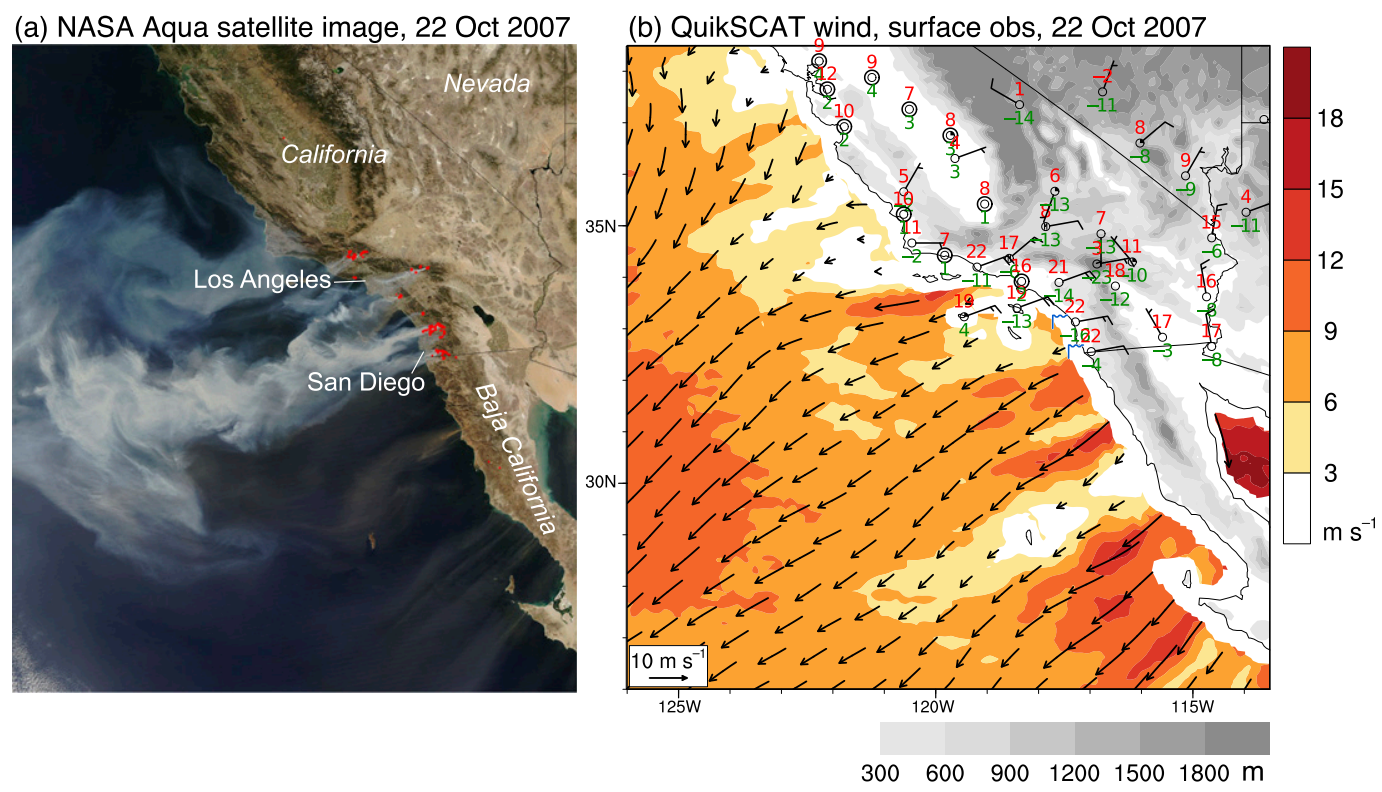

FIG. 1. (a) NASA Aqua satellite image at 2100 UTC 22 Oct 2007 (image obtained from the NASA/MODIS Rapid Response image archive; https://lance.modaps.eosdis.nasa.gov/cgi-bin/imagery/gallery.cgi). Red shaded areas denote active fires. (b) QuikSCAT satellite-derived surface wind (speed shaded in $\mathrm{m} \mathrm{s}^{-1}$ according to the color bar; direction indicated by vectors) at 1321 UTC 22 Oct 2007, observations at 1400 UTC 22 Oct 2007 at selected surface stations showing temperature $\left({ }^{\circ} \mathrm{C}\right.$ in red), dewpoint temperature $\left({ }^{\circ} \mathrm{C}\right.$ in green), wind (barbs; pennant: $25 \mathrm{~m} \mathrm{~s}^{-1}$, full barb: $5 \mathrm{~m} \mathrm{~s}^{-1}$, half barb: $2.5 \mathrm{~m} \mathrm{~s}^{-1}$ ), current weather symbol (blue), and sky cover (circle). The 5-min resolution terrain elevation $(\mathrm{m})$ is shaded in gray.

began between 21 and 23 October in conjunction with strong Santa Ana winds (e.g., Small 1995; Raphael 2003; Westerling et al. 2004; Huang et al. 2009; Hughes and Hall 2010; Abatzoglou et al. 2013) associated with warm, dry conditions and strong (10-15 $\left.\mathrm{m} \mathrm{s}^{-1}\right)$ offshore surface flow (Fig. 1b). The wildfires burned $\sim 4000 \mathrm{~km}^{2}$ and caused widespread destruction to property and infrastructure (California Department of Forestry and Fire Protection 2007; Keeley et al. 2009). The two cold surges occurred east of the Rockies and Sierra Madre Oriental mountains of eastern Mexico on 23-24 October and 29-30 October, respectively, featuring surface northerly winds of 20 $25 \mathrm{~m} \mathrm{~s}^{-1}$ across the Bay of Campeche and Gulf of Tehuantepec (Figs. 2a,b), corresponding to Gulf of Tehuantepec gap flow (e.g., Schultz et al. 1997; Steenburgh et al. 1998; Brennan et al. 2010) and negative normalized 850-hPa temperature anomalies (Figs. 2c,d). ${ }^{1}$ These cold surges maintained persistent cold conditions across Mexico [(National Oceanic and Atmospheric Administration/ U.S. Department of Agriculture) NOAA/USDA 2007, p. 21], with surface minimum temperature $>10^{\circ} \mathrm{C}$ below

\footnotetext{
${ }^{1}$ The normalized anomalies herein were calculated as in Hart and Grumm (2001) from the NCEP CFSR using long-term (19792009) daily climatological mean and standard deviation values comprising the first four harmonics of the annual cycle.
}

normal at some locations in northern and central Mexico (not shown). Widespread heavy rainfall (maximum amounts $>200 \mathrm{~mm}$ ) occurred over portions of the southcentral and southeastern United States during 22-26 October, resulting in flash flooding in some areas and helping to ameliorate severe drought conditions in other areas (Fig. 3; NOAA/USDA 2007, 5-6). Exceptionally heavy rainfall (maximum amounts $>900 \mathrm{~mm}$; Fig. 4) in Chiapas and Tabasco, Mexico, during 29-31 October caused historic flooding, most notably in the complex river catchments of Tabasco, that destroyed crops and infrastructure (Aparicio et al. 2009; Rivera-Trejo et al. 2010). The California wildfires, the first cold surge into Mexico, and the eastern U.S. heavy rainfall were approximately concurrent between 22 and 26 October and corresponded to numerous U.S. daily temperature and precipitation records (Fig. 5).

The EWEs occurred within high-amplitude upper-level flow patterns over North America. This was particularly evident during 22-26 October for the wildfires, the first cold surge, and the eastern U.S. heavy rainfall. During this period, the flow pattern over North America featured prominent ridges near both coasts that bookended a deep trough over the lower Mississippi River valley (Fig. 5). Such flow patterns, characterized by slow-moving and meridionally extensive troughs and ridges, can facilitate 
(a) 2301 UTC 23 Oct 2007

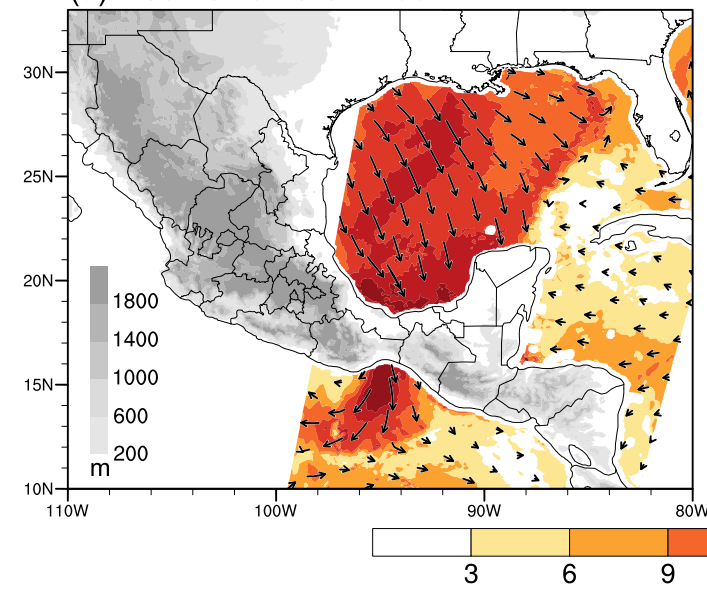

(c) 0000 UTC 24 Oct 2007 (b) 1158 UTC 29 Oct 2007

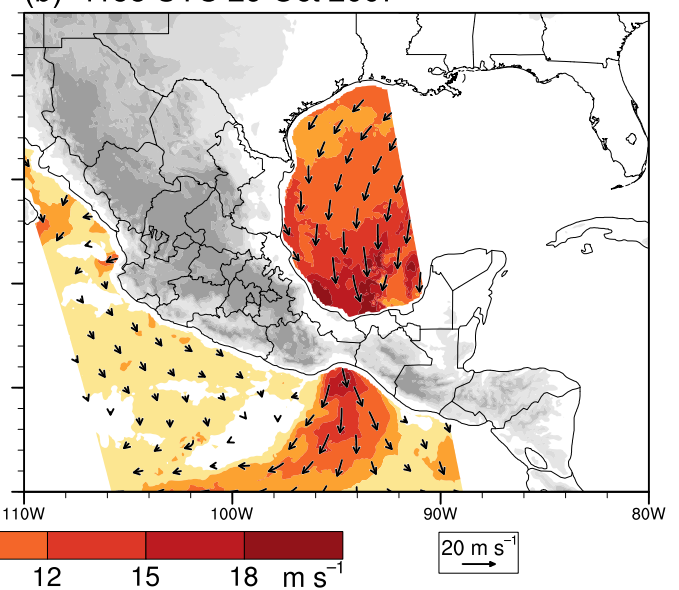

(d) 1200 UTC 29 Oct 2007

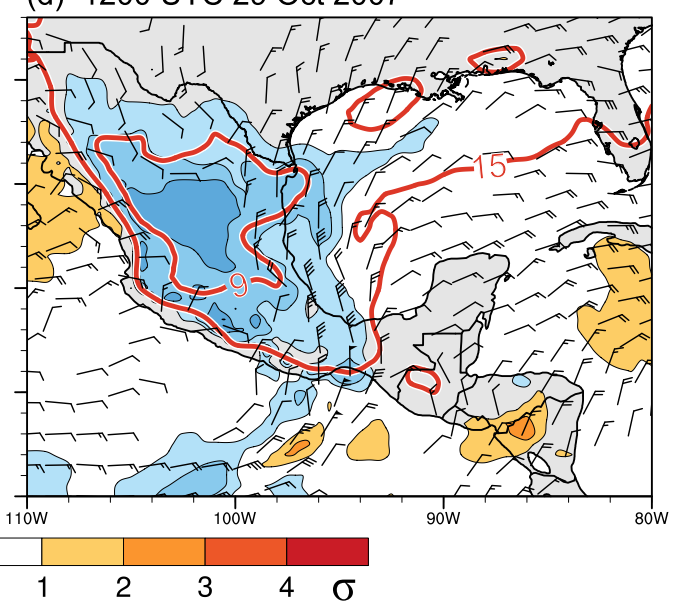

FIG. 2. (top) QuikSCAT satellite-derived surface wind (speed shaded in $\mathrm{m} \mathrm{s}^{-1}$ according to the color bar; direction indicated by vectors) at (a) 2301 UTC 23 Oct and (b) 1158 UTC 29 Oct 2007, and 5-min resolution terrain elevation (gray shading in $\mathrm{m}$ ). (bottom) The $850-\mathrm{hPa}$ temperature $\left(3^{\circ}, 9^{\circ}, 15^{\circ} \mathrm{C}\right.$ contours in red), normalized temperature anomaly relative to the 1979-2009 climatology (shaded in standard deviations according to the color bar), and wind (plotted for wind speeds $\geq 5 \mathrm{~m} \mathrm{~s}^{-1}$; barbs according to the convention in Fig. 1) from the CFSR at (c) 0000 UTC 24 Oct and (d) 1200 UTC 29 Oct 2007.

extensive meridional exchanges of heat and moisture contributing to temperature and precipitation extremes.

High-amplitude flow patterns can form in conjunction with baroclinic Rossby wave trains (RWTs; e.g., Lee and Held 1993; Chang and Yu 1999; Hakim 2003; Glatt and Wirth 2014) along the North Pacific jet (NPJ) and the associated potential vorticity (PV) waveguide (e.g., Martius et al. 2010) through the process of downstream baroclinic development (e.g., Simmons and Hoskins 1979; Orlanski and Chang 1993; Chang and Orlanski 1993; Orlanski and Sheldon 1995; Nielsen-Gammon and Lefevre 1996; Harr and Dea 2009). As individual waves within an upper-level RWT amplify, they can rapidly attain an irreversible configuration and thereby undergo wave breaking (e.g., McIntyre and Palmer 1983, 1984), culminating in the formation of tropopause-level PV streamers (e.g., Appenzeller and Davies 1992; Thorncroft et al. 1993; Wernli and Sprenger 2007). In some cases, Rossby wave dispersion and breaking, often manifested by PV streamer formation, establish favorable conditions for EWEs, such as extreme precipitation events (e.g., Massacand et al. 1998; Knippertz and Martin 2005; Enomoto et al. 2007; Martius et al. 2006, 2008; Wiegand et al. 2011; Martius et al. 2013), heat waves (e.g., Galarneau et al. 2012; Parker et al. 2014), and cold surges (Sprenger et al. 2013).

The NPJ waveguide strengthens as North Pacific baroclinicity increases during the autumnal spinup of the Northern Hemispheric general circulation (Lorenz 1955). Wave packets propagating along this waveguide amplify in conjunction with extratropical cyclogenesis (e.g., Orlanski and Chang 1993; Hakim 2003; Chang 2005; Torn and 


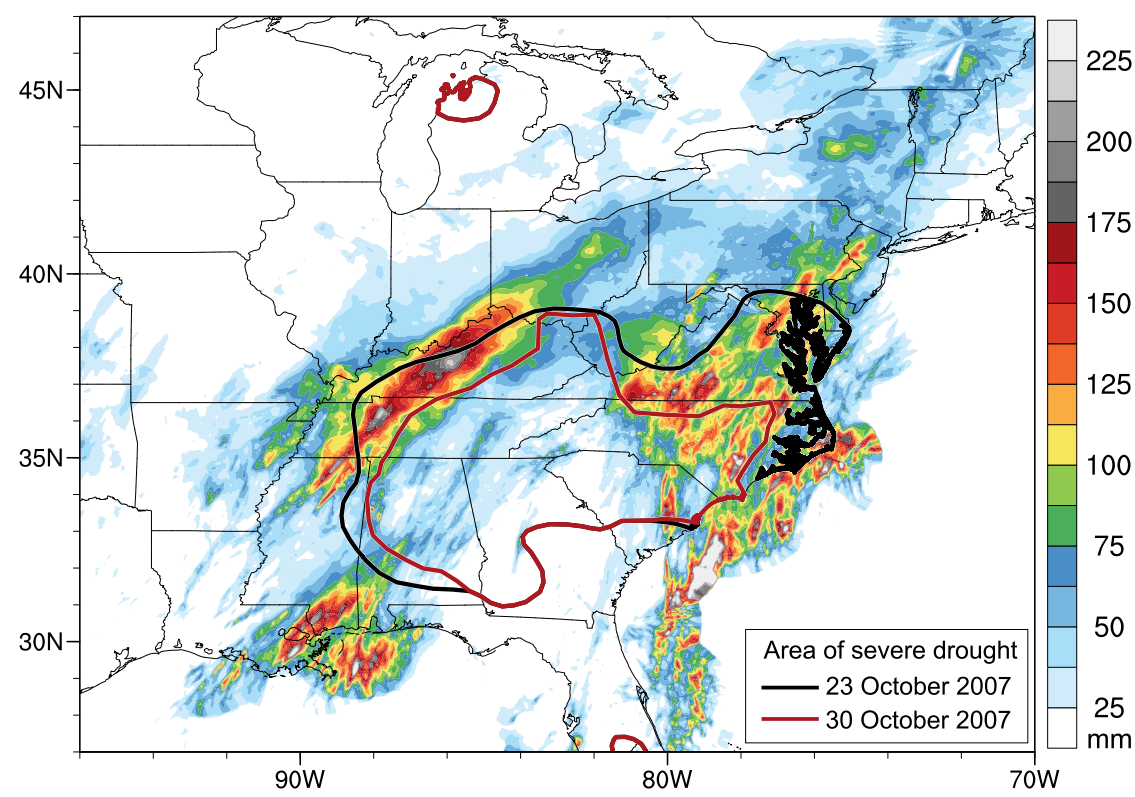

FIG. 3. Accumulated precipitation between 0000 UTC 22 Oct and 0000 UTC 27 Oct 2007 (shaded in mm according to the color bar) from the NCEP Stage-IV analysis and contours denoting areas of severe drought from the National Drought Mitigation Center's U.S. Drought Monitor product for the weeks ending 23 Oct 2007 (black contour) and 30 Oct 2007 (red contour).

Hakim 2015) as well as the recurvature and extratropical transition of tropical cyclones (TCs) (e.g., Klein et al. 2000; Jones et al. 2003; Harr and Dea 2009; Griffin and Bosart 2014; Keller et al. 2014; Archambault et al. 2015;
Quinting and Jones 2016). An interaction between a recurving $\mathrm{TC}$ and the midlatitude flow can induce ridge amplification and jet streak intensification due to diabatic and adiabatic processes (e.g., Atallah and Bosart

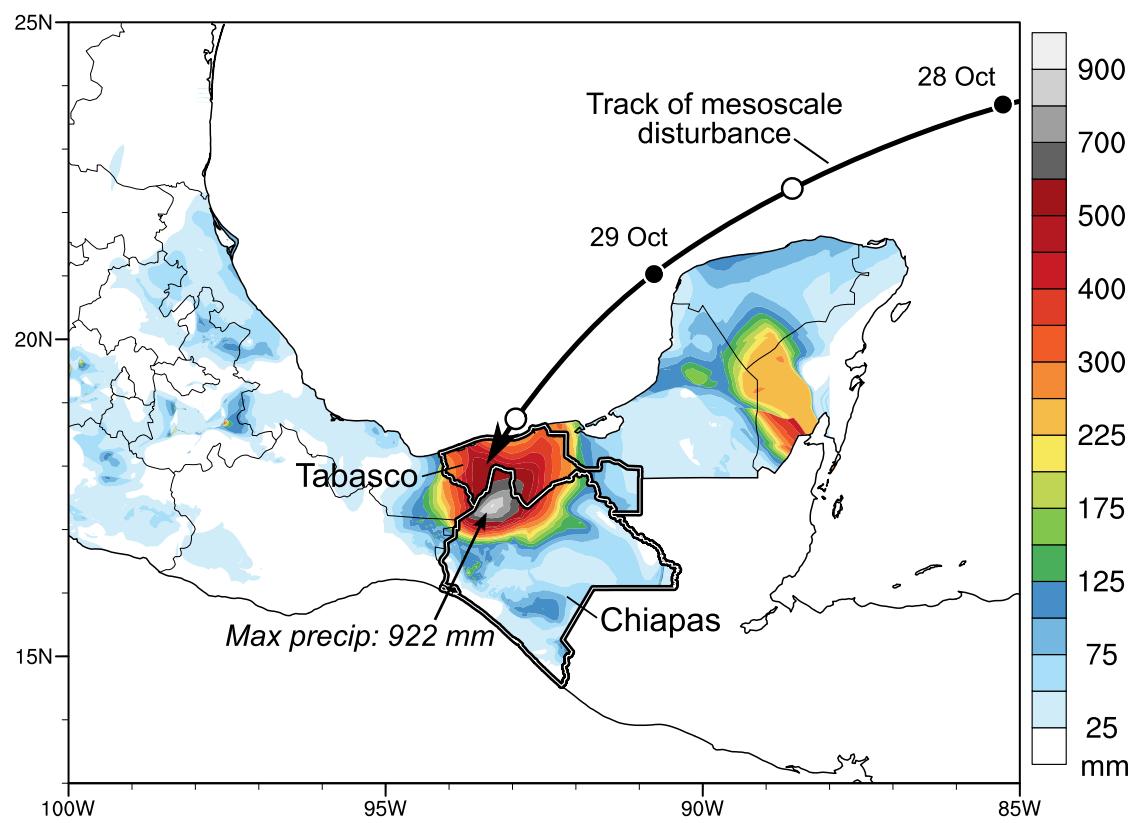

FIG. 4. Accumulated precipitation between 0000 UTC 22 Oct and 0000 UTC 31 Oct 2007 (shaded in mm according to the color bar) from the NASA Daymet dataset. The track of a mesoscale disturbance described in the text during 28-29 Oct is shown, with black (white) dots marking the 0000 UTC (1200 UTC) positions. 


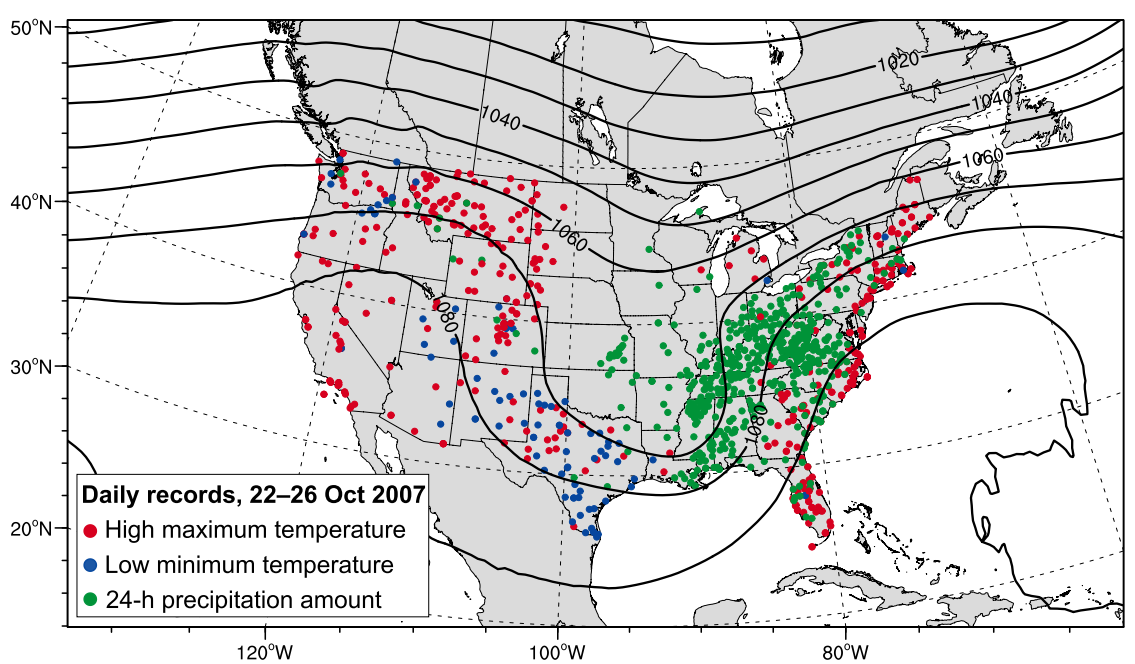

FIG. 5. Time-mean 250-hPa geopotential height (contoured in black every $10 \mathrm{dam}$ ) from the CFSR and daily weather records between 22 and 26 Oct 2007. Red dots mark high maximum temperature records, blue dots mark minimum temperature records, and green dots mark daily precipitation records. All stations have a record length of at least $30 \mathrm{yr}$.

2003; Agusti-Panareda et al. 2004; Riemer et al. 2008; Torn 2010; Grams et al. 2013; Torn et al. 2015; Grams and Archambault 2016). Case studies (e.g., McTaggartCowan et al. 2007; Cordeira and Bosart 2010; Grams et al. 2011; Pantillon et al. 2015; Grams and Blumer 2015; Grams and Archambault 2016), idealized modeling studies (e.g., Riemer et al. 2008; Riemer and Jones 2010), and composite analyses (Archambault et al. 2013, 2015; Torn and Hakim 2015; Quinting and Jones 2016) have demonstrated that this ridge amplification and jet streak intensification can instigate a significant amplification of the downstream large-scale flow. TCmidlatitude flow interactions and the downstream impacts thereof can be associated with reduced forecast skill and elevated forecast uncertainty in numerical models (e.g., Anwender et al. 2008; Harr et al. 2008; Pantillon et al. 2013; Aiyyer 2015; Grams et al. 2015).

Diabatic processes tied to latent heat release within regions of deep ascent and heavy precipitation associated with, for example, a TC (e.g., Grams et al. 2013; Torn et al. 2015) or a warm conveyor belt (WCB; e.g., Carlson 1980; Wernli and Davies 1997; Grams et al. 2011; Madonna et al. 2014b) associated with an extratropical cyclone can play a key role in perturbing the jet stream. In particular, advection of low-PV air by upper-tropospheric divergent outflow above a region of latent heating can amplify a ridge and intensify a jet streak by tightening a PV gradient (e.g., Archambault et al. 2013, 2015). Diabatic ridge amplification can contribute significantly to Rossby wave breaking and associated PV streamer formation (e.g., Massacand et al. 2001; Madonna et al. 2014a). Large forecast errors can result from failures of numerical models to accurately capture diabatic ridge amplification (e.g., Dickinson et al. 1997; Rodwell et al. 2013; Torn et al. 2015; Madonna et al. 2015; Martínez-Alvarado et al. 2016).

The apparent interrelationship of the four EWEs in late October 2007 and their linkage to an antecedent North Pacific and North America flow reconfiguration motivate the current study. They also present a unique opportunity to investigate key multiscale processes facilitating multiple geographically separate but dynamically linked EWEs. Notably, the flow reconfiguration linked to the EWEs was associated with exceptionally low medium-range forecast skill, as illustrated by a marked drop of the day-3 and day-5 anomaly correlation for control forecasts of 250-hPa geopotential height from the NOAA global ensemble forecast system reforecast dataset (Hamill et al. 2013) verifying at 0000 UTC 25 and 26 October, respectively, in a domain over North America (Fig. 6). These were the lowest and second lowest day-3 and day-5 anomaly correlations, respectively, during 2007 , and corresponded to the 0.18 th and 1.52nd percentiles, respectively, for 1985-2014. The low forecast skill provides additional motivation for investigating the processes culminating in the EWEs.

This paper has two primary objectives: 1) to assess how variability of the NPJ on synoptic to near-intraseasonal time scales ( $\sim 10$ days) established a favorable flow configuration for the occurrence of the four EWEs, and 2) to examine the processes governing the occurrence of the four EWEs. We will demonstrate that a high-amplitude RWT across the North Pacific and North America culminated in anticyclonic wave breaking episodes over North America and thereby established favorable 


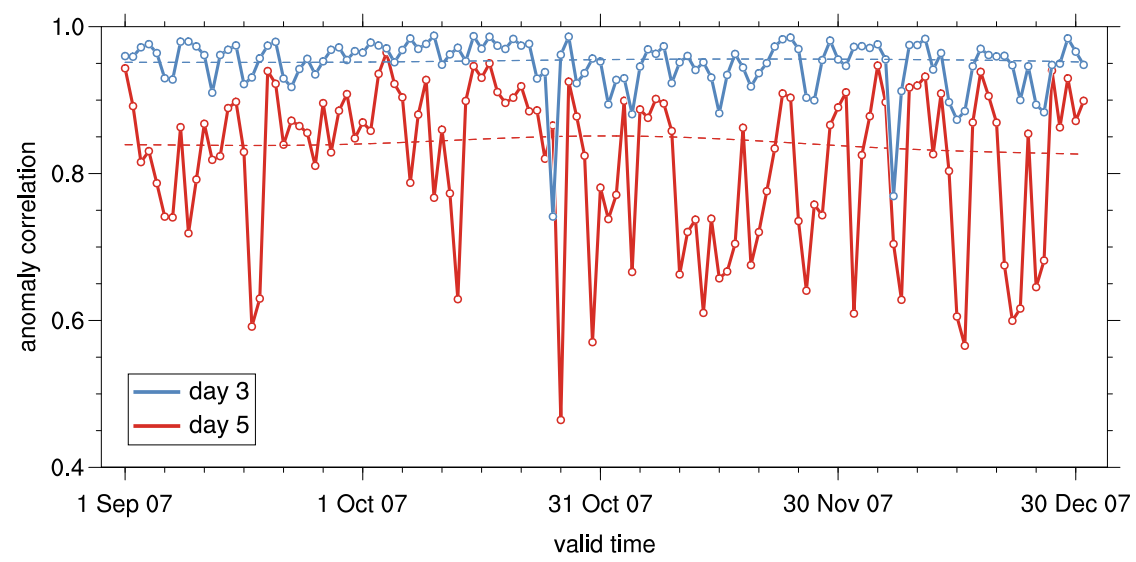

FIG. 6. Time series of the day-3 (blue) and day-5 (red) anomaly correlation of 250-hPa geopotential height in the domain $20^{\circ}-65^{\circ} \mathrm{N}, 140^{\circ}-60^{\circ} \mathrm{W}$ for the control forecast from the NOAA global ensemble forecast system reforecast dataset. Thin dashed lines denote the long-term (1985-2014) daily mean reforecast anomaly correlation values for each lead time. The CFSR was used for verification.

synoptic-scale conditions for the EWEs. Moreover, RWT formation and wave breaking was influenced by polar, midlatitude, and tropical disturbances, including three coherent tropopause-level polar vortices or disturbances (e.g., Hakim and Canavan 2005; Cavallo and Hakim 2009, 2010, 2012, 2013), extratropical cyclones, a diabatic Rossby vortex (e.g., Raymond and Jiang 1990; Moore and Montgomery 2004, 2005; Boettcher and Wernli 2011, 2013, 2015), and western North Pacific TC Kajiki.

\section{Data sources}

The NOAA/National Centers for Environmental Prediction (NCEP) Climate Forecast System Reanalysis (CFSR; Saha et al. 2010) was the primary dataset employed in this study. The CFSR data were obtained on a $0.5^{\circ}$ global grid with 37 isobaric levels at 6-h intervals. Satellite infrared (IR) brightness temperature data were obtained from the GridSat B1 dataset (Knapp et al. 2011), available on a $0.07^{\circ}$ grid from the NOAA/ National Centers for Environmental Information (NCEI; http://www.ncdc.noaa.gov/gridsat/). U.S. precipitation amounts in Fig. 3 were obtained from the 4-km NCEP stage-IV dataset (Lin and Mitchell 2005; archived at the National Center for Atmospheric Research Earth Observing Laboratory, http://www.eol.ucar.edu/), which incorporates both radar and rain gauge reports. Drought information in Fig. 3 was obtained from the National Drought Mitigation Center U.S. Drought Monitor product (http://droughtmonitor.unl.edu/). Precipitation amounts in Fig. 4 were obtained from daily 1-km precipitation analyses from the National Aeronautics and Space Administration (NASA) Daymet dataset (Thornton et al. 1997; archived at the NASA Oak Ridge National Laboratory
Distributed Active Archive Center, http://daac.ornl.gov/). Ocean surface wind observations in Figs. $1 \mathrm{~b}$ and 2a,b were obtained from the NASA QuikSCAT level 2B 12.5-km ocean wind dataset (Fore et al. 2014; archived at the NASA Jet Propulsion Laboratory Physical Oceanography Distributed Active Archive Center, http://podaac.jpl.nasa. gov/). Surface observations over land in Fig. 1b for selected automated surface observing system stations were obtained from the Iowa State University data archive (https://mesonet.agron.iastate.edu/archive/). Daily temperature and precipitation records over the United States (Fig. 5) were obtained from NOAA/NCEI's online daily weather records tool (https://www.ncdc.noaa.gov/cdoweb/datatools/records). The NOAA global ensemble forecast system reforecasts (Hamill et al. 2013) for Fig. 6 were obtained from the NOAA Earth System Research Laboratory (http://www.esrl.noaa.gov/psd/forecasts/ reforecast2/). North Pacific TC track information was obtained from the International Best Track Archive for Climate Stewardship (Knapp et al. 2010).

\section{Antecedent large-scale flow conditions over the North Pacific}

During 13-20 October 2007, anomalously strong westerly North Pacific flow was in place prior to the flow amplification culminating in the EWEs, as evidenced by a belt of positive and negative normalized height anomalies at lower and higher latitudes, respectively (Fig. 7). An area of high geopotential height variance extending southeastward from northeast Asia and eastward across the North Pacific toward western North America marks the primary storm track. The anomalously strong zonal flow configuration is suggestive of a 


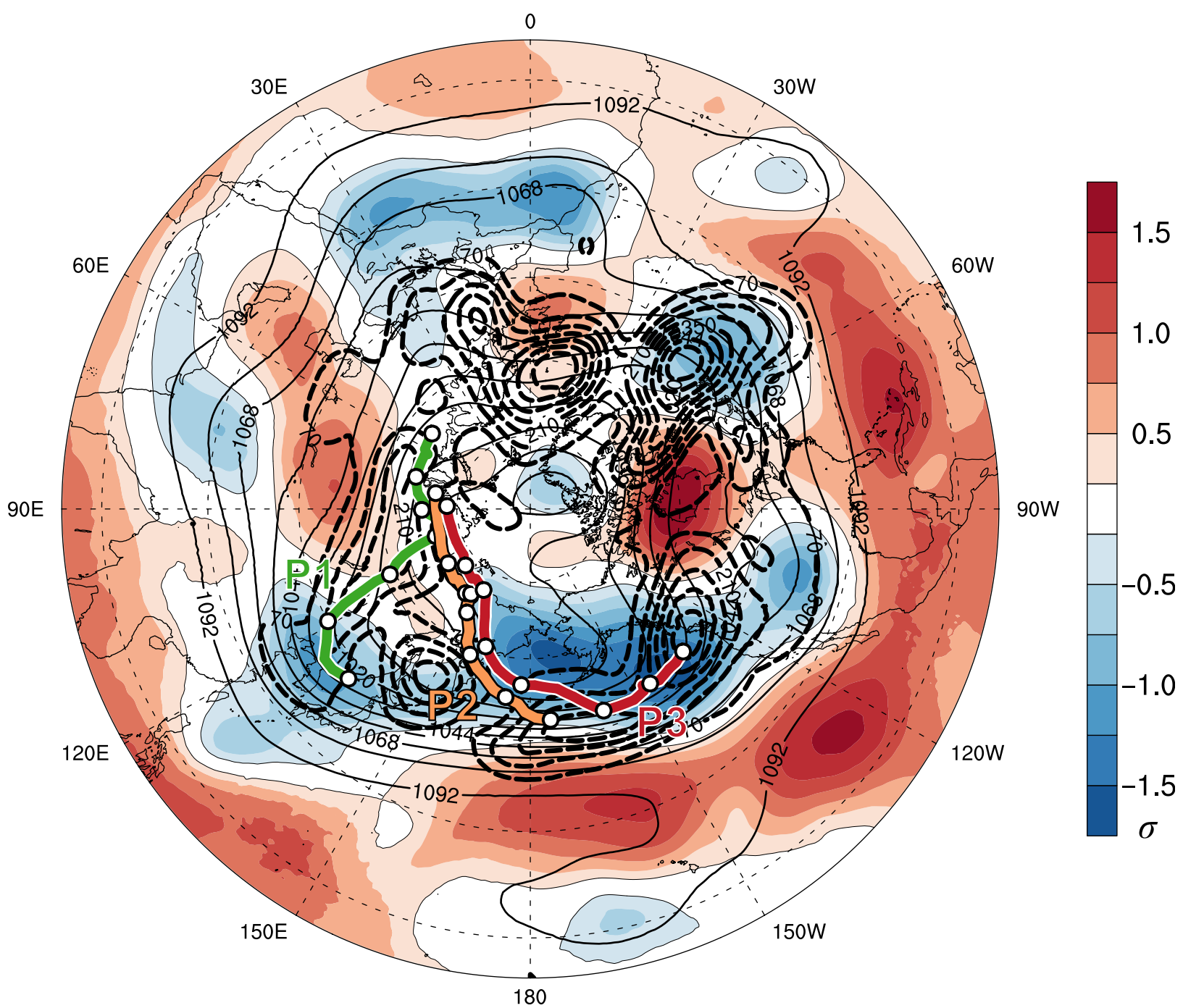

FIG. 7. Mean 250-hPa geopotential height (contoured in black every 12 dam), geopotential height sample variance (thick dashed contours every $70 \mathrm{dam}^{2}$ starting at $70 \mathrm{dam}^{2}$ ), and normalized geopotential height anomaly relative to the 1979-2009 climatology (shaded in standard deviations according to the color bar) for all 6-h CFSR analyses during 0000 UTC 13 Oct-0000 UTC 20 Oct 2007. Manually derived tracks of the minimum potential temperature on the 2-PVU surface for three tropopause-level polar disturbances (P1, P2, and P3) during 0000 UTC 14 Oct-0000 UTC 20 Oct 2007 are overlaid, with white circles marking the 0000 UTC positions.

strong NPJ waveguide conducive to both baroclinic and barotropic instability. Manually derived tracks of the minima of potential temperature $(\theta)$ on the 2-PVU dynamic tropopause (DT; $\theta_{\mathrm{DT}}$ ) for the three tropopauselevel polar disturbances-P1, P2, and P3 - that eventually interacted with the NPJ are shown for reference. These polar disturbances, which originated over northern Russia near $75^{\circ} \mathrm{N}$, enabled early season arctic air to reach lower latitudes and to impinge on the NPJ.

Hovmöller diagrams of the zonal (Fig. 8a) and meridional (Fig. 8b) wind on the DT during October 2007 show that the mostly zonally oriented NPJ strengthened and elongated eastward during 8-20 October discontinuously in conjunction with the recurvature of TCs
Podul, Haiyan, Krosa, and Lingling (tracks displayed in Fig. 8). These TCs were located generally upstream of the NPJ entrance region (Fig. 8a). TCs Podul and Haiyan were associated with short-lived flow amplification (Fig. 8b) without significant NPJ strengthening (Fig. 8a). The recurvatures of TCs Krosa and Lingling were associated with NPJ strengthening and eastward elongation (Fig. 8a).

A marked transition from predominantly zonal to highly meridional North Pacific flow occurred during 18-21 October as TC Kajiki formed and subsequently recurved (Figs. 8a,b). A well-defined RWT was initiated near the east coast of Asia $\left(90^{\circ}-120^{\circ} \mathrm{E}\right)$ on 18 October in connection with the equatorward translation of polar 

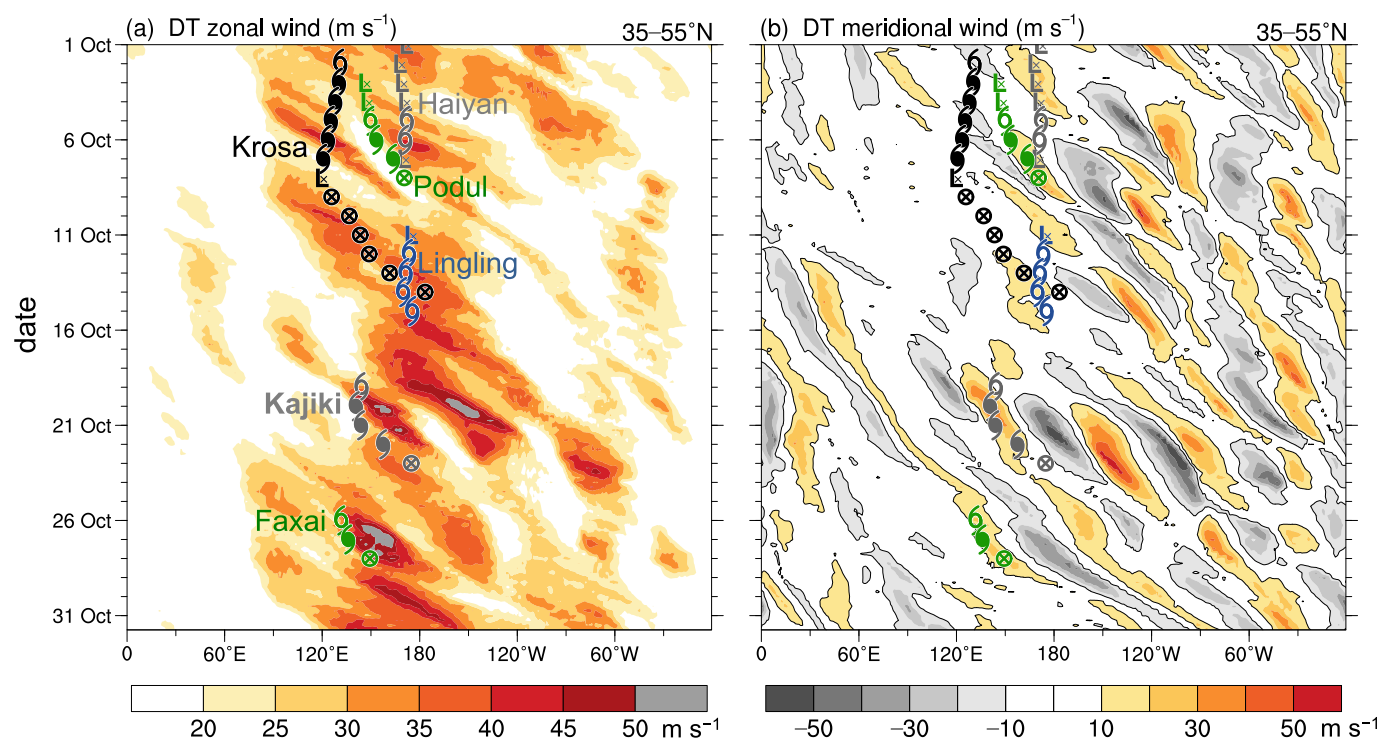

FIG. 8. Hovmöller diagrams of the (a) zonal wind and (b) meridional wind averaged between $35^{\circ}$ and $55^{\circ} \mathrm{N}$ on the 2-PVU surface (shaded in $\mathrm{m} \mathrm{s}^{-1}$ according to the color bars) from the CFSR. The temporal-longitudinal positions of TCs Haiyan, Krosa, Podul, Lingling, Kajiki, and Faxai are overlaid.

disturbance P1 (Fig. 8b). The four North American EWEs ensued as this RWT extended downstream across the North Pacific and North America during the subsequent $\sim 5$ days (Fig. $8 b$ ).

\section{North Pacific flow amplification during 18-23 October 2007}

The North Pacific flow amplification during 18-23 October that culminated in the California wildfires, the first cold surge into Mexico, and the eastern U.S. heavy rains is examined through an analysis of the large-scale flow evolution (Figs. 9-13) and from a Lagrangian perspective though trajectory analysis (Figs. 14-15). Numerous supporting CFSR-based analyses are provided in the online supplemental material.

\section{a. Large-scale flow evolution}

\section{1) ROSSBY WAVE TRAIN FORMATION}

A rapid amplification of the flow across the North Pacific and North America during 18-23 October 2007 is evident in the $\theta_{\mathrm{DT}}$ field (Fig. 9). The onset of this flow amplification during 18-20 October involved perturbations to the initially quasi-zonal NPJ waveguide, identifiable by a large $\theta_{\mathrm{DT}}$ gradient focused within a narrow band $\left(\theta_{\mathrm{DT}}\right.$ values of $\left.\sim 315-340 \mathrm{~K}\right)$ and strong winds $\left(>50 \mathrm{~m} \mathrm{~s}^{-1}\right)$, in conjunction with the equatorward movement of the three polar disturbances, P1, P2, and P3 (Figs. 9a,b). These disturbances, characterized by $\theta_{\mathrm{DT}}$ values of $<300 \mathrm{~K}$ over the eastern coast of Asia, the central
North Pacific, and eastern North Pacific, respectively, were associated with trough and ridge amplification and jet streak intensification along the NPJ.

By 1200 UTC 21 October, a high-amplitude RWT (Fig. 9c), associated with a train of surface cyclones and anticyclones and with amplified thickness and precipitable water (PW) patterns (Fig. 10c), formed across the North Pacific and North America. Downstream of polar disturbances P1 and P2, amplifying uppertropospheric ridges and poleward-extending plumes of warm, moist air were established, and polar disturbance P3 began to deform and meridionally elongate over western North America (Figs. 9c and 10c). At 1200 UTC 21 October, the three polar disturbances were associated with deep downward protrusions of high PV and baroclinic zones, each flanked to the east by a region of ascent and a plume of moist air (Fig. 11). The PV protrusions were associated with deep tropopause folds, corresponding to vertical PV "walls" and concomitant jets in the $\sim 310-350-\mathrm{K}$ isentropic layer, indicative of a superposition of the polar and subtropical jet streams (e.g., Shapiro et al. 1999; Winters and Martin 2014; Handlos and Martin 2016) within the NPJ.

\section{2) WAVE AMPLIFICATION OVER THE WESTERN NORTH PACIFIC}

Polar disturbance P1 induced cyclogenesis and cyclonic wave breaking along the eastern coast of Asia, during 18-21 October (Figs. 9a-c and 10a-c). By 1200 UTC 21 October, a ridge developed along the NPJ $\left(\theta_{\mathrm{DT}}\right.$ values $>330)$ immediately downstream near the date 


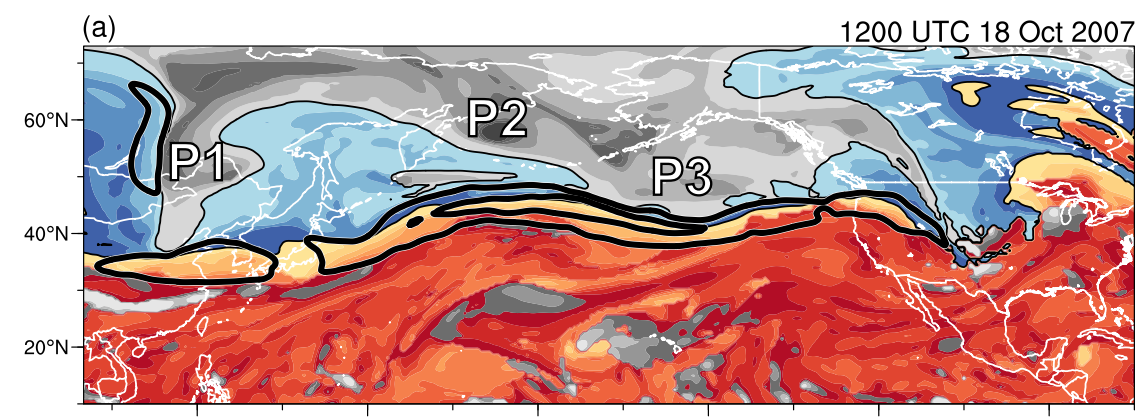

(b)

0000 UTC 20 Oct 2007

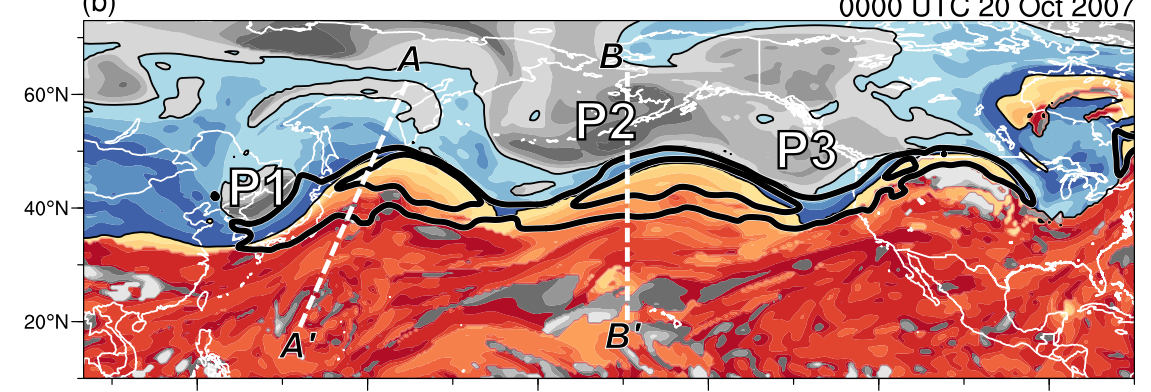

(c)

1200 UTC 21 Oct 2007
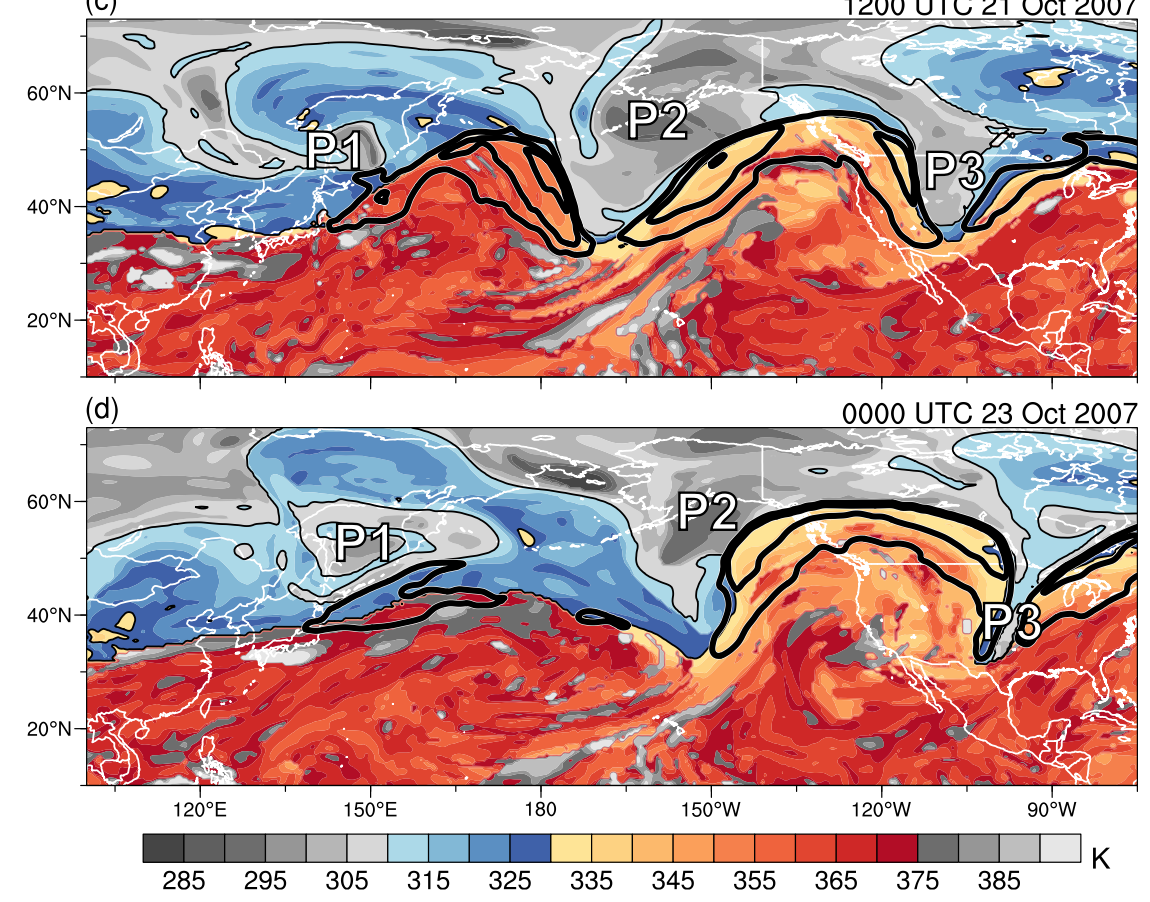

FIG. 9. Potential temperature (shaded in $\mathrm{K}$ according the color bar) and wind speed (contoured in black every $20 \mathrm{~m} \mathrm{~s}^{-1}$ starting at $50 \mathrm{~m} \mathrm{~s}^{-1}$ ) on the 2-PVU surface from the CFSR at (a) 1200 UTC 18 Oct, (b) 0000 UTC 20 Oct, (c) 1200 UTC 21 Oct, and (d) 0000 UTC 23 Oct 2007. The locations of the three tropopause-level polar disturbances (P1, P2, and P3) are labeled in each panel. The white lines $\mathrm{A}-\mathrm{A}^{\prime}$ and $\mathrm{B}-\mathrm{B}^{\prime}$ mark the locations of the cross sections depicted in Fig. 13.

line, and a northwesterly jet streak intensified on the eastern flank of the ridge (Fig. 9c). Moreover, a prominent high-latitude cyclonically wrapping ridge developed poleward of the NPJ $\left(\theta_{\text {DT }}\right.$ values $\left.<330\right)$ over eastern Russia in connection with cyclonic wave breaking. During 20-21 October, TC Kajiki recurved and became embedded within the southern portion of the warm sector of an extratropical cyclone centered 

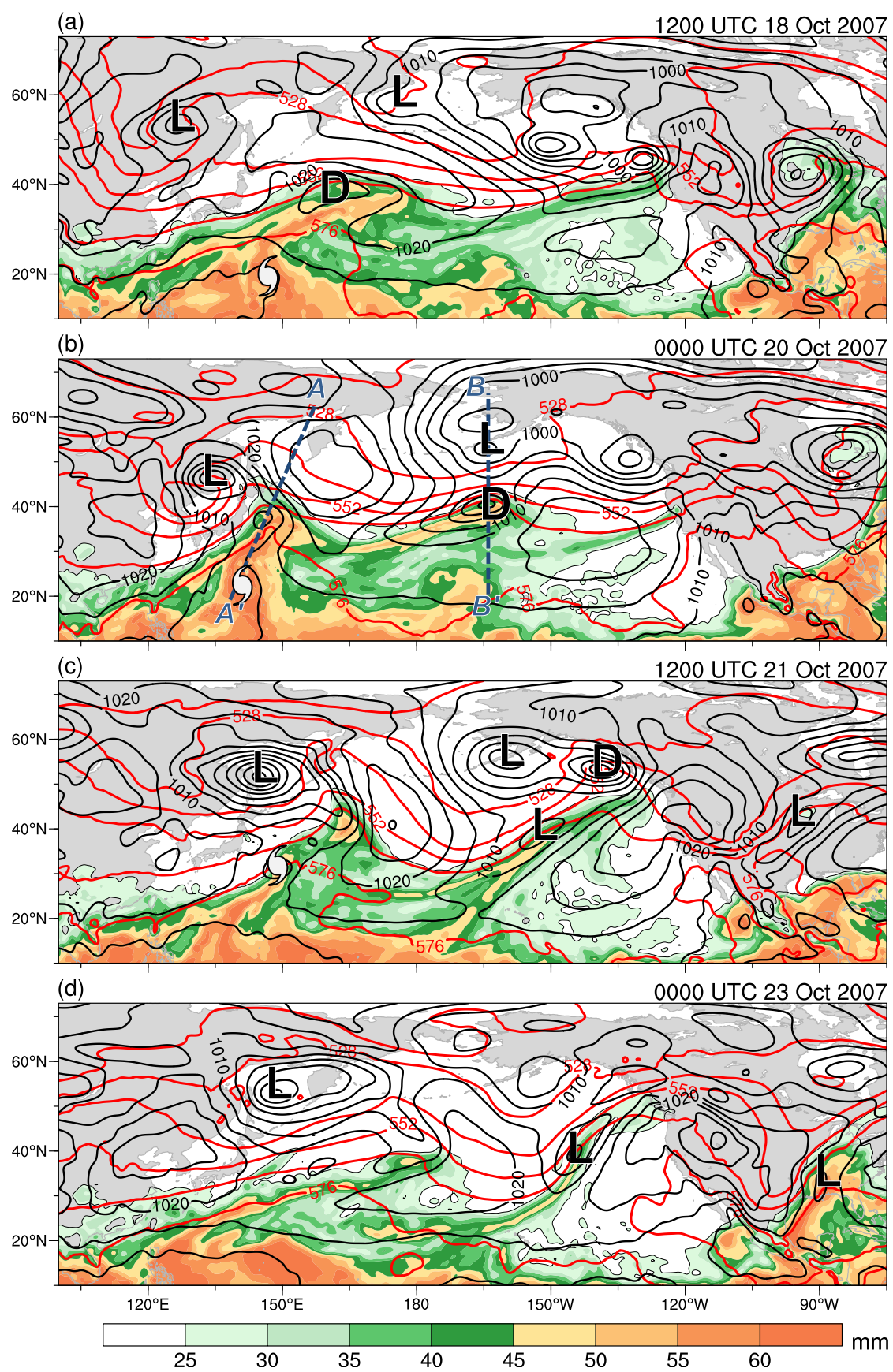

FIG. 10. Sea level pressure (contoured in black every $5 \mathrm{hPa}$ ), precipitable water (shaded in $\mathrm{mm}$ according the color bar), $1000-500-\mathrm{hPa}$ thickness (contoured in red every 10 dam) from the CFSR at (a) 1200 UTC 18 Oct, (b) 0000 UTC 20 Oct, (c) 1200 UTC 21 Oct, and (d) 0000 UTC 23 Oct 2007. Selected sea level pressure minima are marked by the L symbols, a diabatic Rossby vortex feature is indicated by the D symbol, and TC Kajiki is indicated by the TC symbol. The blue lines $\mathrm{A}-\mathrm{A}^{\prime}$ and $\mathrm{B}-\mathrm{B}^{\prime}$ in (b) mark the locations of the cross sections depicted in Fig. 13.

over eastern Asia. This configuration enabled moist tropical air (PW values $>50 \mathrm{~mm}$ ) from the vicinity of TC Kajiki to stream poleward toward a warm frontal zone extending to the southeast from the extratropical cyclone center (Figs. 10b,c and 12b,c). Accordingly, expansive clouds and precipitation, inferred from low IR brightness temperatures, and an associated strong radial divergent outflow signature in the $250-\mathrm{hPa}$ 


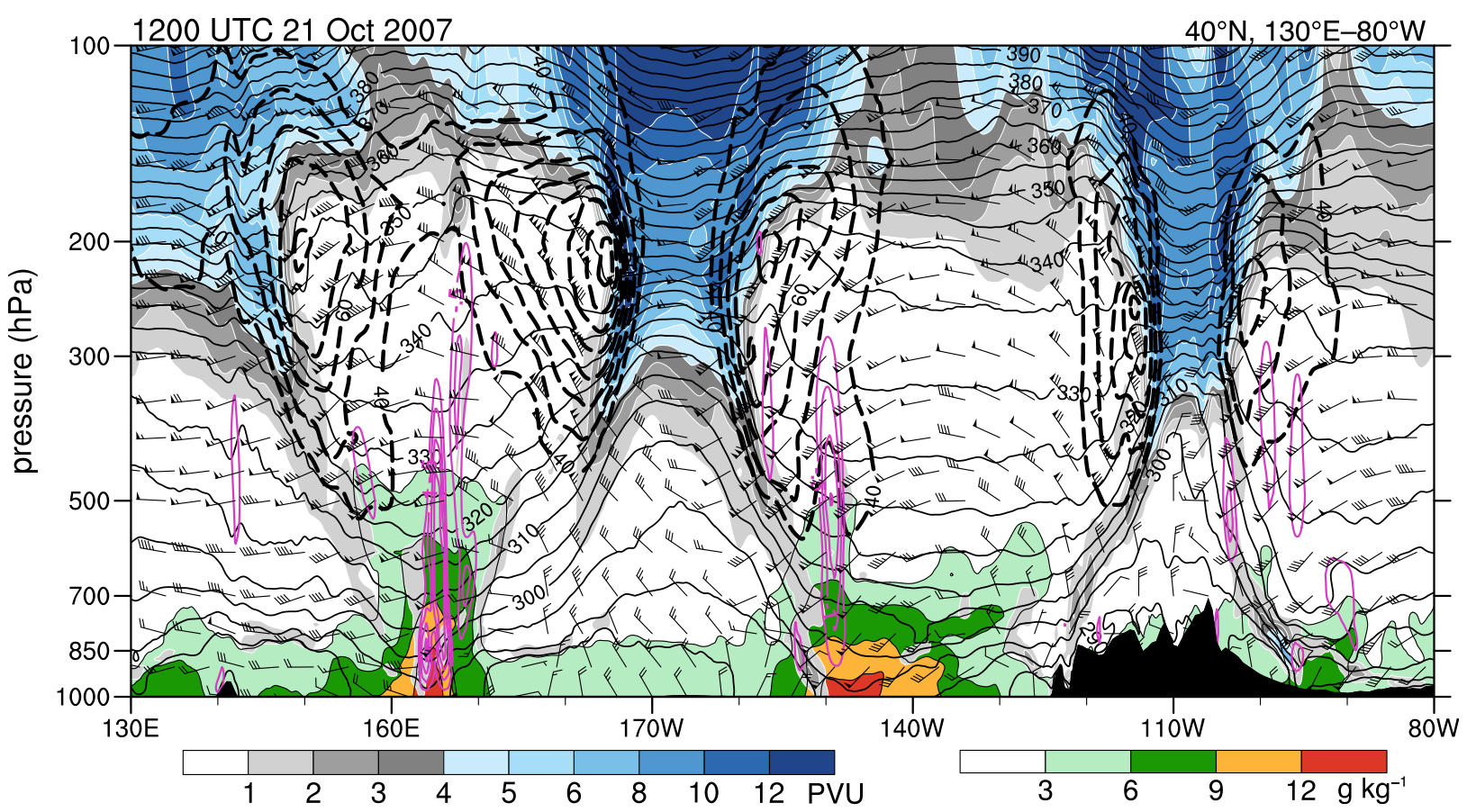

FIG. 11. Cross section at $1200 \mathrm{UTC} 21$ Oct 2007 from $130^{\circ} \mathrm{E}$ to $80^{\circ} \mathrm{W}$ along $40^{\circ} \mathrm{N}$ displaying PV (shaded in PVU according to the left color bar), specific humidity (shaded in $\mathrm{g} \mathrm{kg}^{-1}$ according to the right color bar), potential temperature (contoured in black every $5 \mathrm{~K}$ ), upward vertical velocity (contoured in magenta every $0.5 \mathrm{~Pa} \mathrm{~s}^{-1}$ starting at $0.5 \mathrm{~Pa} \mathrm{~s}^{-1}$ ), and horizontal wind ( $\mathrm{m} \mathrm{s}^{-1}$; barbs according to the convention in Fig. 1; wind speed denoted by dashed black contours every $10 \mathrm{~m} \mathrm{~s}^{-1}$ starting at $40 \mathrm{~m} \mathrm{~s}^{-1}$ ) from the CFSR.

irrotational wind developed near the frontal zone, most prominently near a frontal wave feature southeast of the extratropical cyclone center (Figs. 12b,c). ${ }^{2}$ At 1200 UTC 21 October, deep ascent was present in the vicinity of a baroclinic zone near the terminus of a moisture plume extending poleward from TC Kajiki (Fig. 13a). Negative PV advection by the divergent outflow contributed to ridge amplification downstream of polar disturbance P1 (Figs. 12b,c).

\section{3) WAVE AMPLIFICATION OVER THE EASTERN NORTH PACIFIC}

Polar disturbance P2 appeared to interact with a fastmoving baroclinic surface cyclone that resembled a diabatic Rossby vortex over the central North Pacific during 20-21 October. As is characteristic of diabatic Rossby vortices (Boettcher and Wernli 2013 and references therein), this cyclone (referred to hereafter as a diabatic Rossby vortex) developed and propagated rapidly eastward between 18 and 20 October on the anticyclonic shear side of the jet stream along the $1000-500-\mathrm{hPa}$

\footnotetext{
${ }^{2}$ The irrotational wind was computed via a Helmholtz decomposition of the global 250-hPa horizontal flow using spherical harmonics functions in the NCAR Command Language (UCAR/ NCAR/CISL/TDD 2016).
}

thickness gradient within a plume of high $(>50 \mathrm{~mm})$ PW (Figs. 10a,b). Moreover, the diabatic Rossby vortex developed in the absence of a significant upper-level precursor (i.e., weak quasigeostrophic forcing for ascent; not shown) and consistently featured low IR brightness temperatures (Figs. 12a,b). Between 20 and 21 October, the diabatic Rossby vortex intensified and moved rapidly northeastward into the Gulf of Alaska as it interacted with polar disturbance P2 (Figs. 10b,c), and contributed to upper-tropospheric ridge amplification downstream over the eastern North Pacific and western North America (Figs. 9b,c). The intensification and movement of the diabatic Rossby vortex and the downstream ridge amplification coincided with the development of a prominent thermal ridge and a poleward-extending plume of high PW over the eastern North Pacific east of a southwestnortheast-elongated cold front trailing to the southwest of the diabatic Rossby vortex (Figs. 10b,c). Clouds and precipitation, inferred from low IR brightness temperatures, and associated upper-tropospheric divergent outflow were consistently evident near the diabatic Rossby vortex center and along the trailing front (Figs. 12b,c). Negative PV advection by the divergent outflow contributed to ridge amplification (Figs. 12b,c). At 0000 UTC 20 October, a plume of moist air extended toward a poleward-sloping frontal zone that stretched 


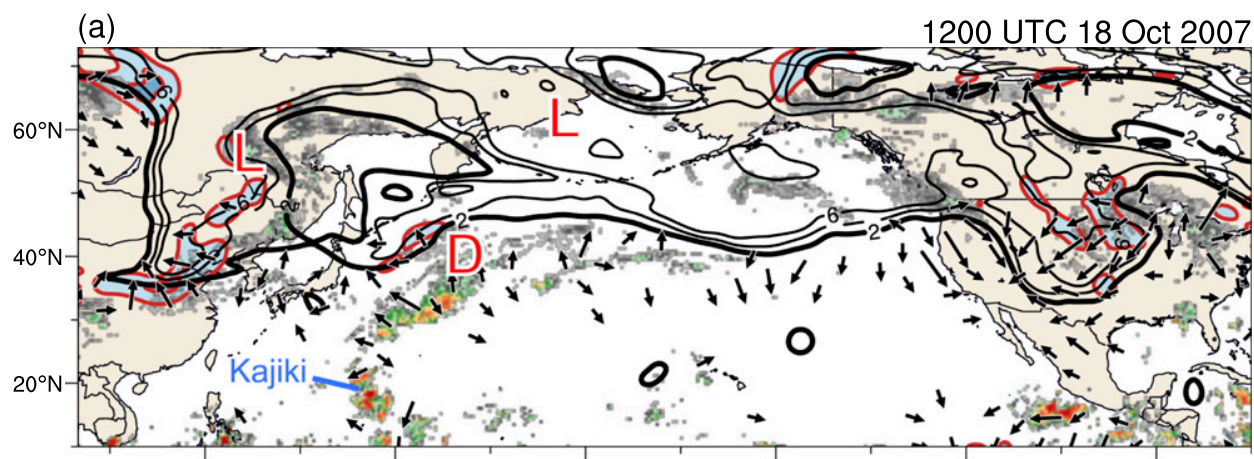

(b)

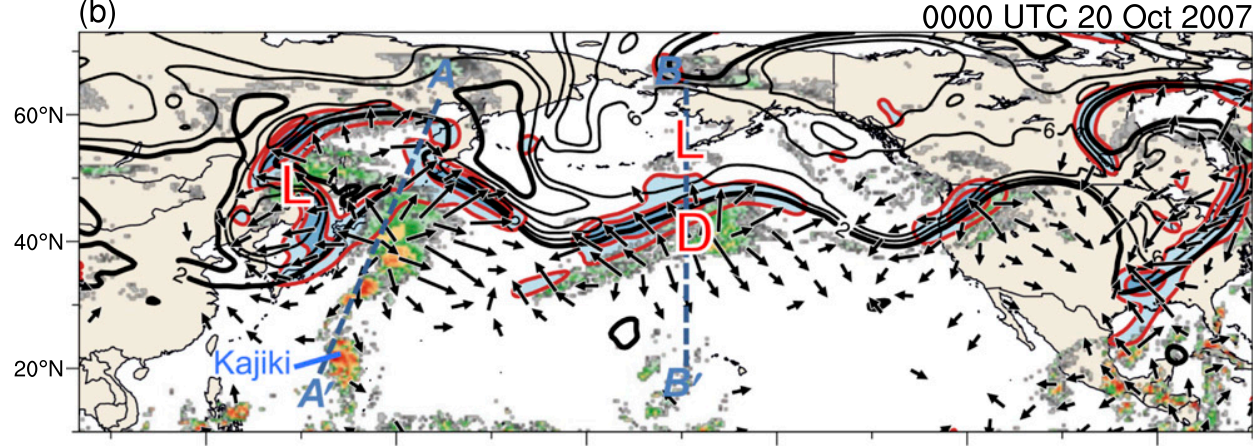

(c)

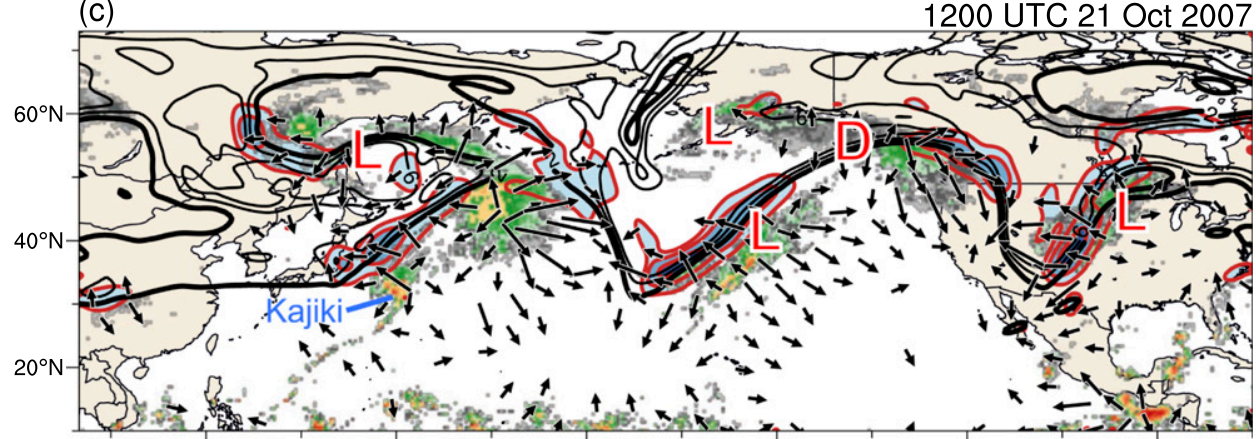

(d)

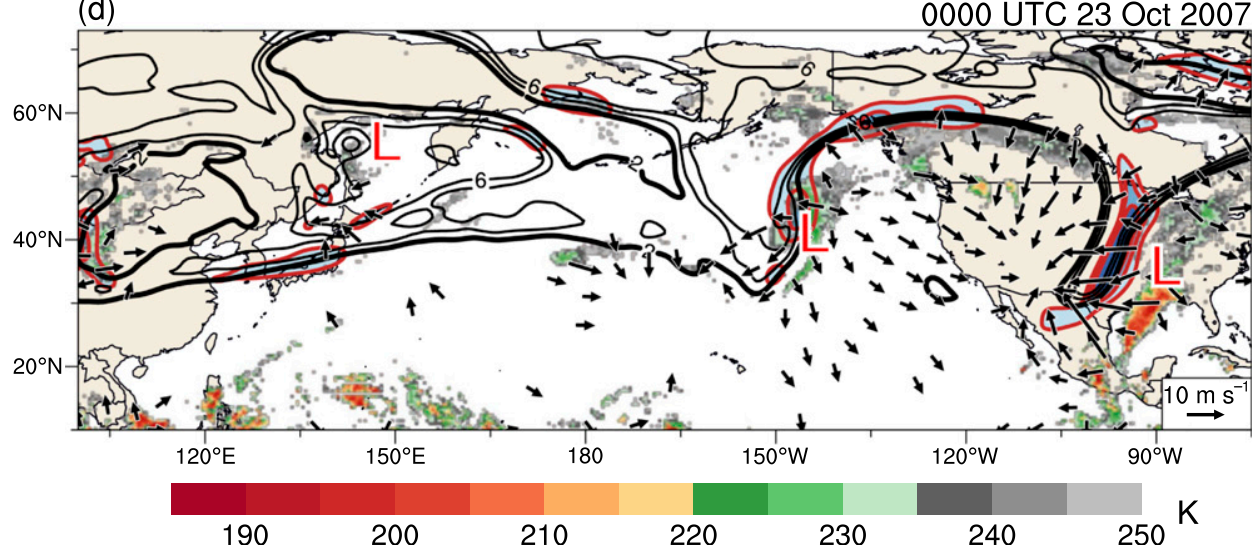

FIG. 12. Infrared brightness temperature from the NASA Gridsat dataset (shaded in K according to the color bar) overlaid by 250 -hPa PV (contoured in black every 2 PVU between 2 and 8 PVU), irrotational wind vectors (plotted for magnitudes $\geq 5 \mathrm{~m} \mathrm{~s}^{-1}$; reference vector in lower right), and PV advection by the irrotational wind $\left[-0.5,-1.5,-3.0 \mathrm{PVU}(6 \mathrm{~h})^{-1}\right.$ contours shown in red with light blue shading] from the CFSR at (a) 1200 UTC 18 Oct, (b) 0000 UTC 20 Oct, (c) 1200 UTC 21 Oct, and (d) 0000 UTC 23 Oct 2007. Symbols marking key surface features are as in Fig. 10. The blue lines $A-A^{\prime}$ and $B-B^{\prime}$ in (b) mark the locations of the cross sections depicted in Fig. 13. 
(a) 0000 UTC 20 Oct 2007

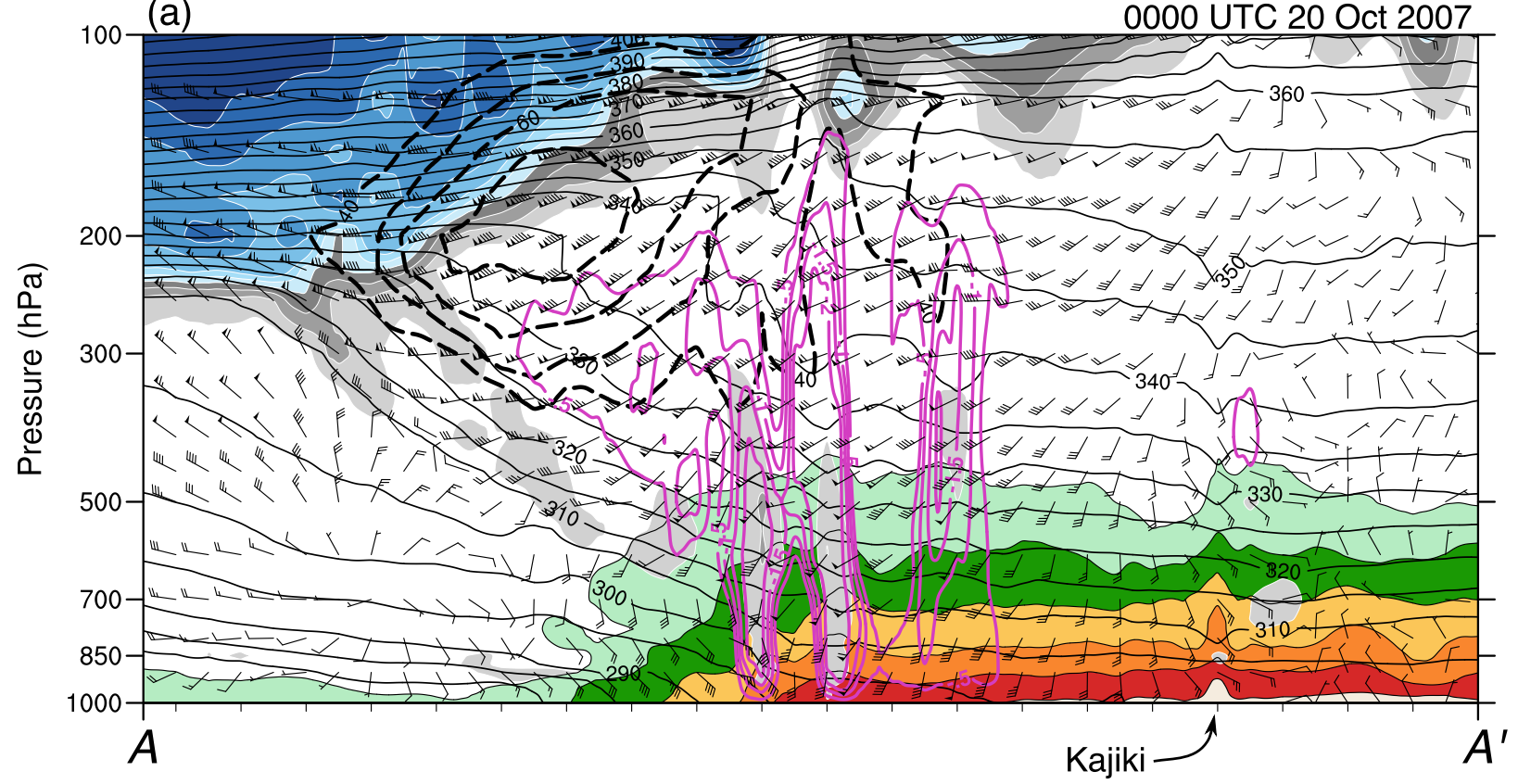

(b)

0000 UTC 20 Oct 2007

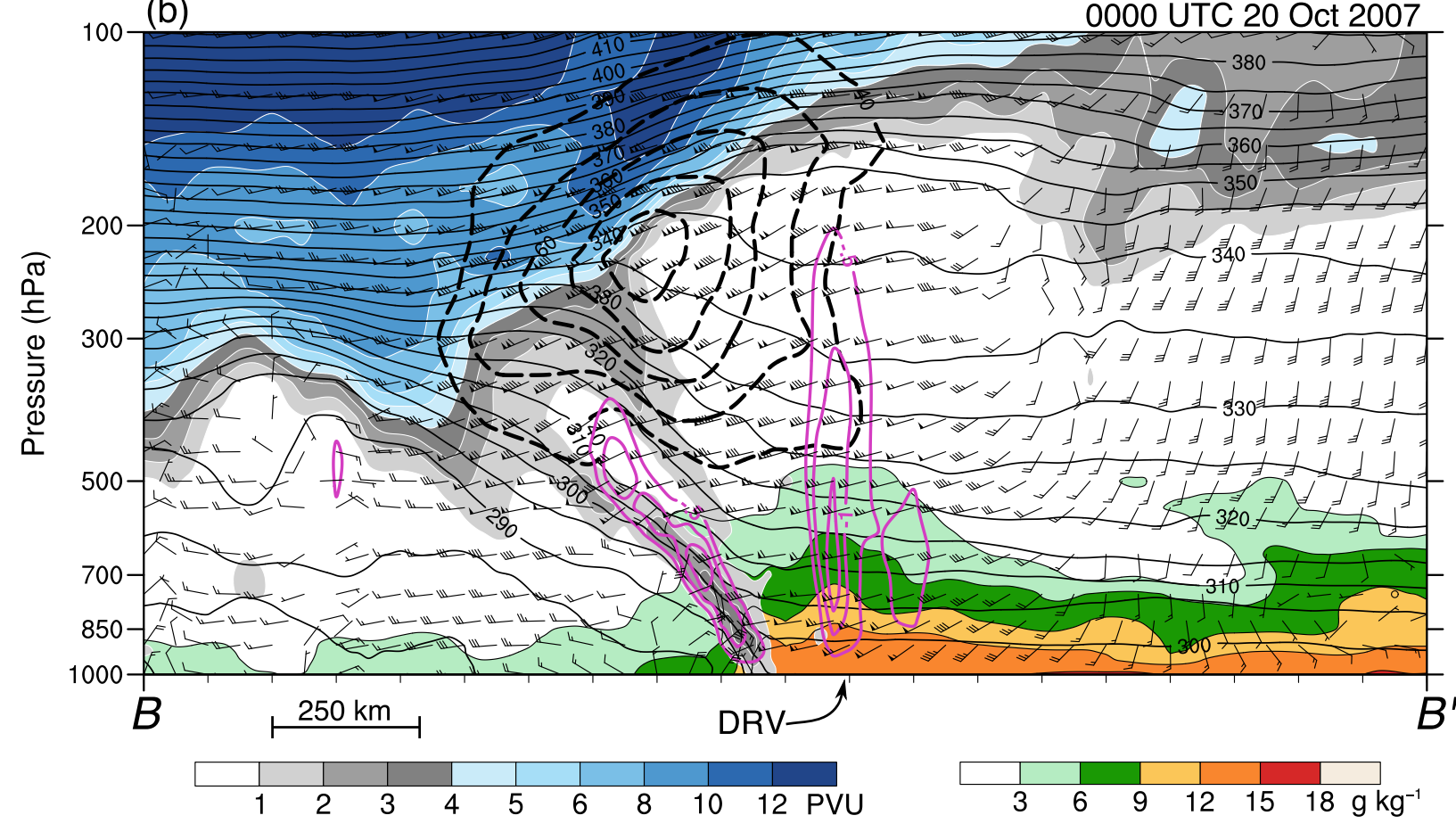

FIG. 13. As in Fig. 11, but for cross sections along the lines (a) A-A' and (b) B-B' shown in Figs. 9b, 10b, and 12 b at 0000 UTC 20 Oct 2007. The locations of TC Kajiki and the DRV are indicated on the respective $x$ axes.

upward from the surface near the diabatic Rossby vortex center to an area of high PV associated with polar disturbance P2 (Fig. 13b). Two distinct areas of deep ascent-one sloping poleward along the frontal zone and the other upright well equatorward of the frontal zone-reflect frontally and convectively forced ascent, respectively.

\section{4) ANTICYCLONIC WAVE BREAKING OVER NORTH AMERICA}

During 21-23 October, the eastern North Pacific ridge continued to amplify in conjunction with downstream baroclinic development linked to the aforementioned western North Pacific ridge amplification. Specifically, 
the downstream baroclinic development was associated with central North Pacific trough amplification immediately upstream of polar disturbance $\mathrm{P} 2$ and with the concomitant development of a secondary extratropical cyclone along the cold front trailing the diabatic Rossby vortex (Figs. 9b-d and 10b-d). In response, the eastern North Pacific ridge amplified, expanded zonally, and slowed its eastward translation. This process coincided with warm-air advection, poleward water vapor transport, precipitation, and divergent outflow accompanying the secondary extratropical cyclone within the western portion of the ridge (Figs. 10b-d and 12b-d). By 0000 UTC 23 October, the ridge had expanded across western North America and had begun to undergo anticyclonic wave breaking, with polar disturbance P3 transforming into a narrow, meridionally elongated PV streamer downstream over the central United States (Fig. 9d). The anticyclonic wave breaking was associated with a flow reconfiguration that resulted in the California wildfires, the first Mexican cold surge, and the eastern U.S. heavy rainfall. The flow pattern over North America featured 1) a strong anticyclone centered over the Great basin that supported Santa Ana wind conditions over Southern California and strong northerly flow and coldair advection east of the Rockies, and 2) a corridor of poleward flow and water vapor transport into the central and eastern United States immediately downstream of the PV streamer (Fig. 10d).

\section{b. Lagrangian perspective}

A Lagrangian perspective on the flow amplification during 18-23 October 2007 is provided through backward air parcel trajectories ending in the NPJ (Figs. 14-15) calculated from the CFSR using the NOAA HYSPLIT model (Draxler and Hess 1998; Stein et al. 2015). Trajectories were released at 1200 UTC 21 October (blue and red lines) and at 0000 UTC 23 October (gray and green lines) from upper-level $(350-175 \mathrm{hPa})$ grid points in domains over the western and eastern North Pacific, respectively, where the wind speed exceeded $30 \mathrm{~m} \mathrm{~s}^{-1}$ (Fig. 14). Selected subsets of trajectories are hereafter examined. The trajectories plotted in red and green were defined as WCB trajectories, ascending $\geq 600 \mathrm{hPa}$ within a 48 -h period (e.g., Wernli and Davies 1997; Madonna et al. 2014b). These trajectories featured low PV (Fig. 15d) and exhibited strong ascent and diabatic heating (Figs. 15a,c), corresponding to negative PV advection by the irrotational wind and ridge amplification (Figs. 12b-d). The trajectories plotted in blue terminated in the lower stratosphere $(\mathrm{PV}>2$ PVU; PVU $=10^{-6} \mathrm{~K} \mathrm{~kg}^{-1} \mathrm{~m}^{2} \mathrm{~s}^{-1}$ ) and passed poleward of $60^{\circ} \mathrm{N}$ at least once. These parcels resided above $300 \mathrm{hPa}$ and exhibited relatively small variations in $\theta$
(Figs. 15a,c). For the time series in Fig. 15, values stated hereafter refer to the median values.

The WCB air parcels associated with the red trajectories originated in the moist [specific humidity $(q)$ of $\sim 14 \mathrm{~g} \mathrm{~kg}^{-1}$ ] tropical lower troposphere $(\sim 900 \mathrm{hPa}$ on average) in close proximity to TC Kajiki at 1200 UTC 18 October, and during the subsequent $72 \mathrm{~h}$ extended poleward, ascended to near $250 \mathrm{hPa}$, and underwent anticyclonic motion in conjunction with ridge amplification near the date line (Figs. 14a,b and 15a). The ascent coincided with a $q$ decrease to near $0 \mathrm{~g} \mathrm{~kg}^{-1}$ (Fig. 17b), a $\theta$ increase of $\sim 39 \mathrm{~K}$ (Fig. 15c), and a wind speed increase of $\sim 50 \mathrm{~m} \mathrm{~s}^{-1}$ (Fig. 15e). The concurrent changes in $q$ and $\theta$ along the trajectories indicate condensation and diabatic heating due to latent heat release. The PV along these trajectories began at $\sim 0.1 \mathrm{PVU}$, a characteristic value for a well-mixed tropical boundary layer, increased slightly during the period of ascent and diabatic heating, and then dropped back to $\sim 0.1 \mathrm{PVU}$ as the air parcels entered the NPJ (Fig. 15d).

Following Madonna et al. (2014b), a calculation was performed to check the consistency between the diabatic heating and the expected latent heating associated with the $q$ decrease along the trajectories using the following relation:

$$
\Delta \theta=-\left(p_{0} / p\right)^{\kappa}\left(L / C_{p}\right) \Delta q
$$

where $p_{0}$ is the reference pressure of $1000 \mathrm{hPa}$, $\kappa=0.286, L$ is the latent heat of vaporization, and $C_{p}$ is the specific heat capacity of water at constant pressure. Assuming a latent heat of vaporization of $2.5 \times 10^{6} \mathrm{~J} \mathrm{~kg}^{-1}$ and pressure of $732 \mathrm{hPa}$ (i.e., the time average of the median parcel pressure along the entire trajectory), a decrease in $q$ of $14 \mathrm{~g} \mathrm{~kg}^{-1}$ corresponds to a $\theta$ increase of $\sim 40 \mathrm{~K}$, closely matching the $\sim 39-\mathrm{K}$ increase depicted in Fig. 15c.

The stratospheric air parcels associated with the blue trajectories generally originated poleward of $55^{\circ} \mathrm{N}$ over central Russia and followed wavy paths, with many moving equatorward toward the NPJ in conjunction with the equatorward progression of polar disturbance $\mathrm{P} 1$ and then poleward over the eastern coast of Russia in connection with a high-latitude ridge amplification linked to cyclonic wave breaking (Fig. 14a). The air parcels subsequently traveled equatorward in conjunction with trough amplification on the downstream flank of the ridge, becoming juxtaposed with the red WCB trajectories by 1200 UTC 21 October (Fig. 14b). The juxtaposition of the two groups of parcels corresponded to an increasing $\theta_{\mathrm{DT}}$ gradient and a developing jet streak (Figs. 9c and 14b).

The stratospheric air parcels associated with the gray trajectories originated at 0000 UTC 20 October near the 
(a) 0000 UTC 20 Oct 2007

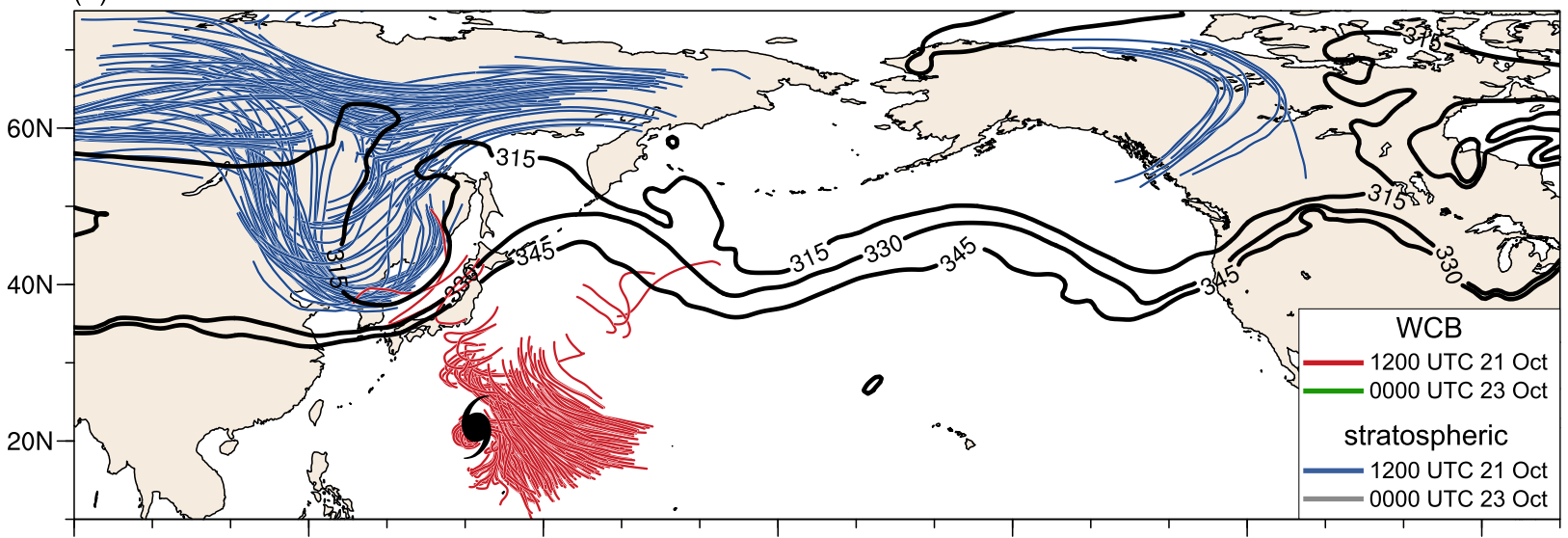

\section{(b) 1200 UTC 21 Oct 2007}

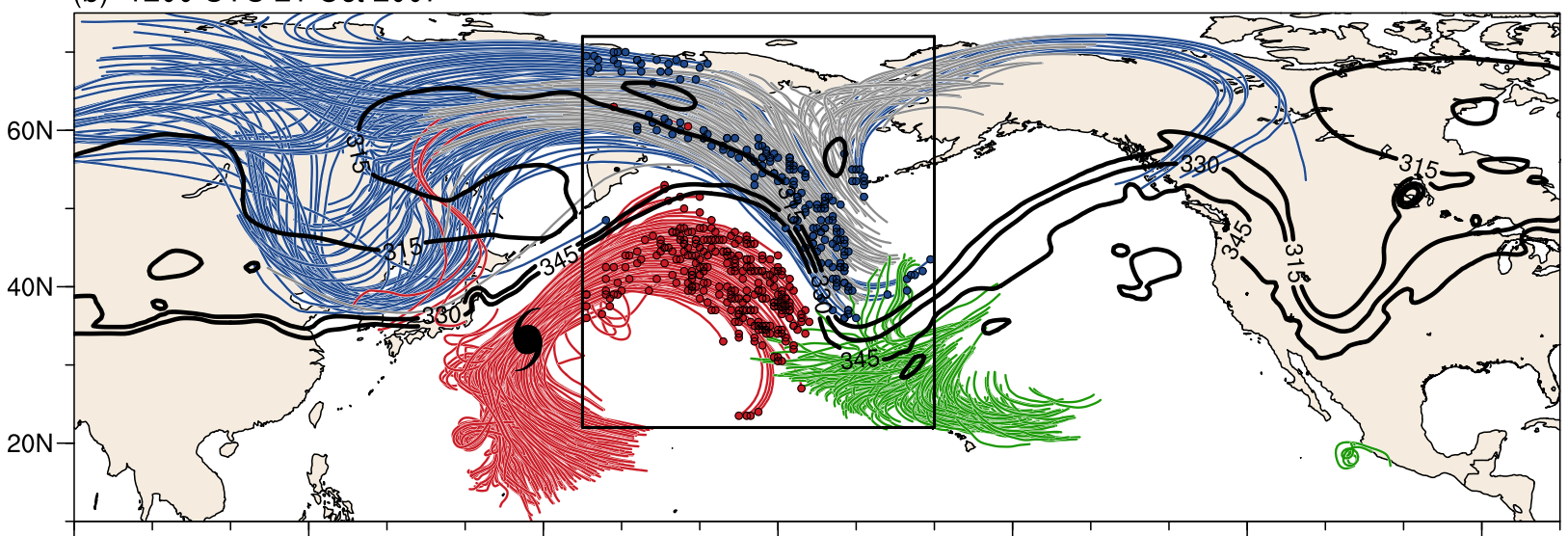

\section{(c) 0000 UTC 23 Oct 2007}

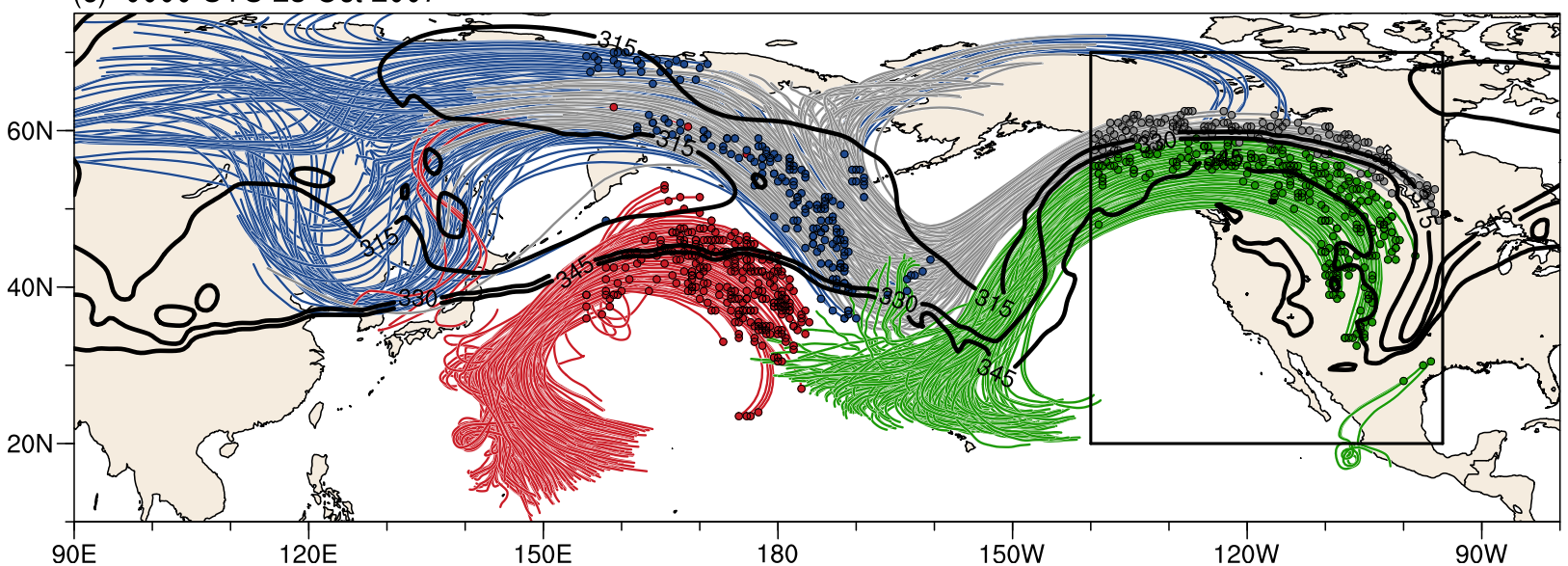

FIG. 14. Potential temperature on the DT (315-, 330-, and 345-K contours in black) from the CFSR at (a) 0000 UTC 20 Oct, (b) 1200 UTC 21 Oct, and (c) 0000 UTC 23 Oct 2007 and positions for CFSR-based 72-h HYSPLIT backward trajectories released from grid points between 350 and $175 \mathrm{hPa}$ with wind speed $>30 \mathrm{~m} \mathrm{~s}^{-1}$ at 1200 UTC 21 Oct 2007 (blue and red lines) within the box in (b) and at 0000 UTC 23 Oct 2007 (gray and green lines) within the box in (c). Trajectories are plotted from their start time until (a) 0000 UTC 20 Oct 2007 , (b) 1200 UTC 21 Oct 2007, and (c) their end time. The trajectories exhibiting ascent of $>600 \mathrm{hPa}$ in $48 \mathrm{~h}$ (i.e., WCB trajectories) are colored in red and green, and the trajectories with an ending PV value of $>2$ PVU that passed poleward of $60^{\circ} \mathrm{N}$ (i.e., stratospheric trajectories) are colored in blue and gray. The release locations of the trajectories are marked by the colored dots. To improve readability, $10 \%$ (5\%) of the WCB (stratospheric) trajectories were randomly selected and plotted. The TC symbol in (a) and (b) marks the location of TC Kajiki. 

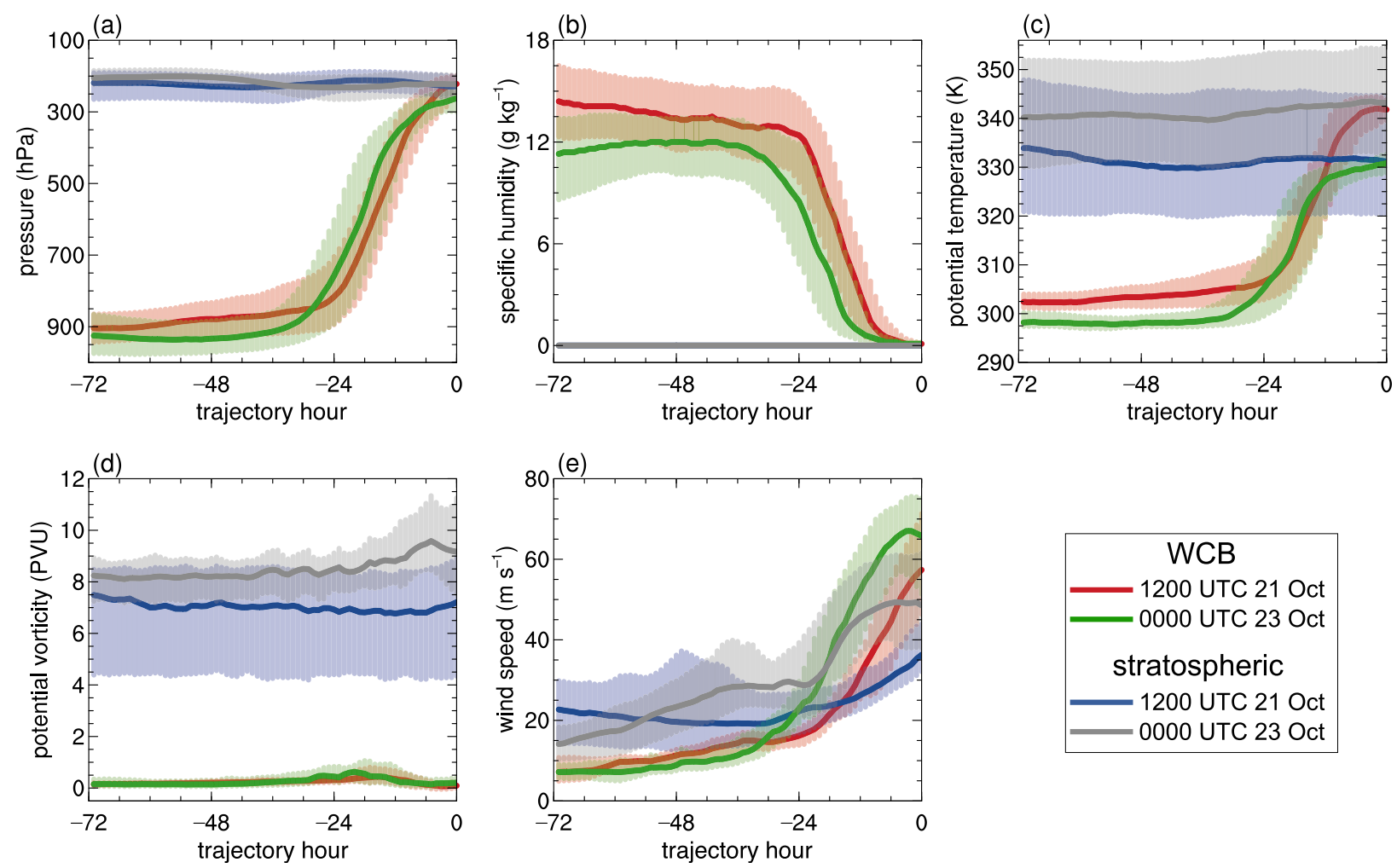

FIG. 15. Time series of parcel (a) pressure (hPa), (b) specific humidity $\left(\mathrm{g} \mathrm{kg}^{-1}\right)$, (c) potential temperature (K), (d) PV (PVU), and (e) wind speed $\left(\mathrm{m} \mathrm{s}^{-1}\right)$ for the four groups of 72-h backward trajectories displayed in Fig. 14. The curves denote the median, and the shadings denote the interquartile range.

crest of the high-latitude ridge over northeastern Russia, and during the subsequent $36 \mathrm{~h}$ moved far southeastward over the central North Pacific into the base of the amplifying trough east of the date line (Fig. 14b). The air parcels then turned sharply northeastward downstream of the trough axis and extended into the crest of the amplifying eastern North Pacific and western North America ridge (Fig. 14c). These air parcels had similar characteristics to those of the other stratospheric air parcels but higher pressure, $\theta$, and PV values (Figs. 15a,c,d).

The WCB air parcels associated with the green trajectories were transported poleward in the lower troposphere ( $\sim 900 \mathrm{hPa}$; Fig. 15a) over the subtropical eastern North Pacific immediately downstream of the amplifying trough east of the date line during 2021 October (Figs. 14b,c). The parcels moved rapidly northeastward across the eastern North Pacific and underwent anticyclonic motion, coinciding with pronounced eastern North Pacific and western North America ridge amplification between 21 and 23 October (Figs. 14b,c). Similar to the other WCB air parcels, these air parcels underwent deep ascent (Fig. 15a) and exhibited signatures of condensation and latent heat release, as indicated by a decrease $q$ of $\sim 12 \mathrm{~g} \mathrm{~kg}^{-1}$ (Fig. 15b) and a $\theta$ increase of $\sim 33 \mathrm{~K}$ (Fig. 15c). The observed $\theta$ increase is very close to the expected latent heating $(\sim 32 \mathrm{~K})$ indicated by Eq. (1). By 0000 UTC 23 October, the WCB air parcels were juxtaposed with stratospheric air parcels within the high-amplitude ridge extending into western North America (Fig. 14c), corresponding to a tightened PV gradient and a strengthened jet streak.

\section{Wildfires, first cold surge, and eastern U.S. heavy rainfall}

\section{a. Flow evolution over North America during} 21-25 October 2007

As hitherto described, the North Pacific and North American flow amplification during 18-23 October, manifested by a RWT, culminated in anticyclonic wave breaking over North America. The corresponding flow reconfiguration (Fig. 16) featured pronounced uppertropospheric ridge amplification and lower-tropospheric anticyclogenesis over western North America and the transformation of polar disturbance P3 into a PV streamer over the central United States. The resulting 
flow pattern enabled the instigation of the California wildfires, the first cold surge, and the eastern U.S. heavy rainfall. The lower-tropospheric anticyclogenesis, centered over the U.S. Great Basin (Figs. 16a,c), was associated with warm conditions over western North America, evident by a prominent $1000-500-\mathrm{hPa}$ thickness ridge and +1-2 standard deviation $850-\mathrm{hPa}$ normalized temperature anomalies (Figs. 16b,d). Strong offshore flow and Santa Ana conditions (Fig. 1b) were established over the Southern California wildfire region on the equatorward flank of the Great basin anticyclone, while strong northerly flow and cold-air advection east of the Rockies linked to the first cold surge developed on the eastern flank of the anticyclone (Figs. 16b,d). The cold surge was identifiable by the formation of a pronounced thickness trough and by the progression of -2 to -4 standard deviation $850-\mathrm{hPa}$ normalized temperature anomalies across the Great Plains and into Mexico (Figs. 16d,f). The cold surge likely involved ageostrophic terrain-channeling effects east of the Rockies (Colle and Mass 1995); quantification of these effects is outside the scope of the current study.

A poleward-directed corridor of strong vertically (1000-300 hPa) integrated water vapor transport and collocated PW values of $>50 \mathrm{~mm}$ extended across the Gulf of Mexico into the Tennessee Valley and Ohio Valley immediately east of the PV streamer between a lower-tropospheric trough east of the steamer and a developing $850-\mathrm{hPa}$ anticyclone off the eastern U.S. coast (Figs. 16c). The strong water vapor transport and high PW supported heavy rainfall in the presence of warm-air advection (Fig. 16d) and associated quasigeostrophic forcing for ascent east of the PV streamer (not shown). Between 23 and 25 October, the PV streamer drifted slowly eastward and began to cut off (Figs. 16c,e). Accordingly, the corridor of water vapor transport persisted and migrated slowly eastward (Fig. 16e), continuing to support heavy rainfall.

At 0000 UTC 23 October, a surface-based mixed layer below $850 \mathrm{hPa}$ was present in the offshore flow that sustained the wildfires (Fig. 17). The climatological lower-tropospheric marine inversion was offshore, while a stable layer was near $700 \mathrm{hPa}$ along and inland of the coast, likely signifying warming subsidence associated with the Great Basin anticyclogenesis. East of the Rockies, the PV streamer corresponded to a deep narrow downward protrusion of high $\mathrm{PV}$ and an associated baroclinic zone extending from above $200 \mathrm{hPa}$ into the lower troposphere delimiting a deep dome of cold air east of the Rockies connected to the cold surge (Fig. 17). The PV protrusion was flanked by steep PV walls and concomitant jets, likely reflecting a polar-subtropical jet superposition. The deep baroclinic structure illustrates that the PV streamer and cold surge were manifestations of the same troposphere-deep system. Immediately east of the streamer and cold surge, the corridor of strong water vapor transport and high PW was manifested by a plume of moist air ( $q$ values of $>15 \mathrm{~g} \mathrm{~kg}^{-1}$ ) collocated with deep poleward flow and ascent (Fig. 17).

A map of the 0000 UTC position of the 572-dam 1000-500-hPa thickness contour during 21-25 October depicts a poleward surge of warm air across western North America associated with the amplifying upperlevel ridge and a terrain-channeled, equatorwarddirected surge of cold air (i.e., the first cold surge) east of the Rockies and the Sierra Madre Oriental mountains (Fig. 18a). Between 23 and 25 October, the thickness contour moved rapidly equatorward into southern Mexico (Fig. 18a) as the first cold surge traversed the Chivela Pass into the Gulf of Tehuantepec (Figs. 2a,c).

\section{b. Lagrangian perspective}

The wildfires, the first cold surge, and the heavy rainfall over the eastern United States are further explored through 96-h backward HYSPLIT air parcel trajectories corresponding to each EWE (Fig. 19) released every $6 \mathrm{~h}$ between 0000 UTC 23 and 0000 UTC 24 October. For the wildfires (red trajectories) and the cold surge (blue trajectories), trajectories were released from grid points below $800 \mathrm{hPa}$ in boxes over Southern California and eastern and southern Mexico, respectively. The wildfire trajectories were released from grid points with $<15 \%$ relative humidity. The cold surge trajectories were released from grid points with a meridional wind value of $<-15 \mathrm{~m} \mathrm{~s}^{-1}$. For the heavy rainfall over the eastern United States (green trajectories), trajectories were released from grid points below $300 \mathrm{hPa}$ with $>90 \%$ relative humidity within a box over the eastern United States and were required to exhibit a $5 \mathrm{~g} \mathrm{~kg}^{-1}$ decrease in $q$ (i.e., precipitation generation) in the final $24 \mathrm{~h}$. In Fig. 17, locations where trajectories crossed the 0000 UTC 23 October cross section are indicated by color-coded plus symbols.

The wildfire air parcels, originating in the middle troposphere ( $\sim 700 \mathrm{hPa}$; Fig. $19 \mathrm{c})$ over the midlatitude North Pacific, underwent sharp anticyclonic motion within the ridge/anticyclone over western North America into Southern California (Fig. 19a). Between -96 and $-24 \mathrm{~h}$, these air parcels ascended $\sim 150 \mathrm{hPa}$ (Fig. 19c), coinciding with a $q$ decrease of $\sim 1.5 \mathrm{~g} \mathrm{~kg}^{-1}$ (Fig. 19d), a relative humidity increase from $63 \%$ to $75 \%$ (Fig. 19f), a $\theta$ increase of $\sim 12 \mathrm{~K}$ (Fig. 19e), and a temperature decrease of $\sim 16 \mathrm{~K}$ (Fig. $19 \mathrm{~g}$ ). The changes in $q$ and $\theta$ likely reflect condensation and latent heating as the parcels ascended. Between -24 and $0 \mathrm{~h}$, the air parcels moved into the wildfire region, abruptly descending to 
(a)

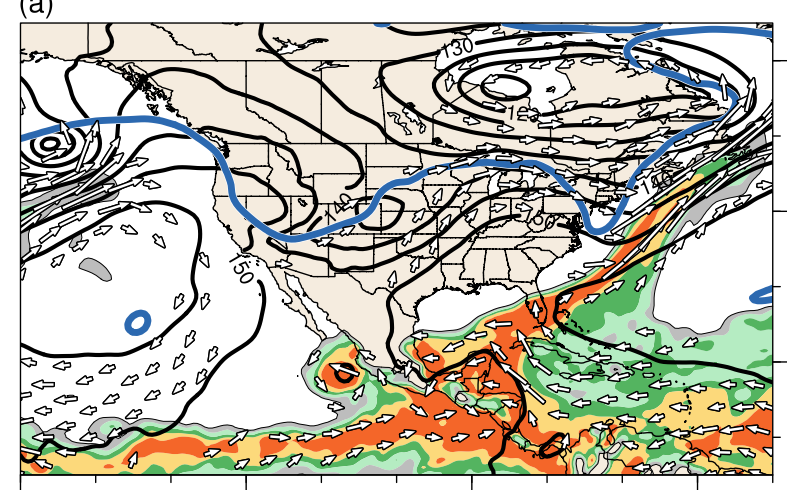

(c)

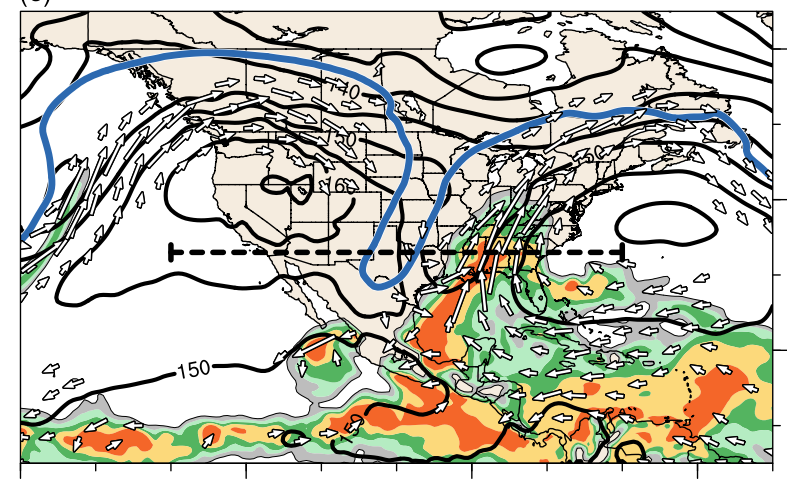

(e)

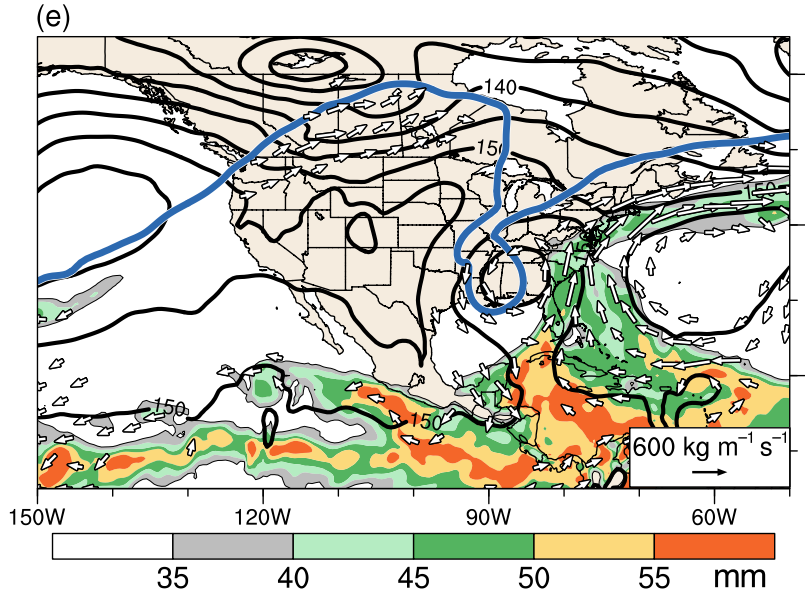

(b)

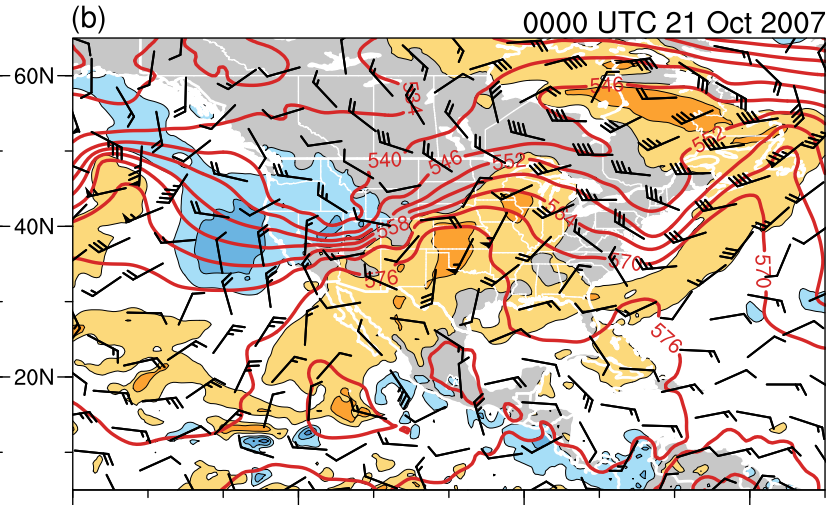

(d)

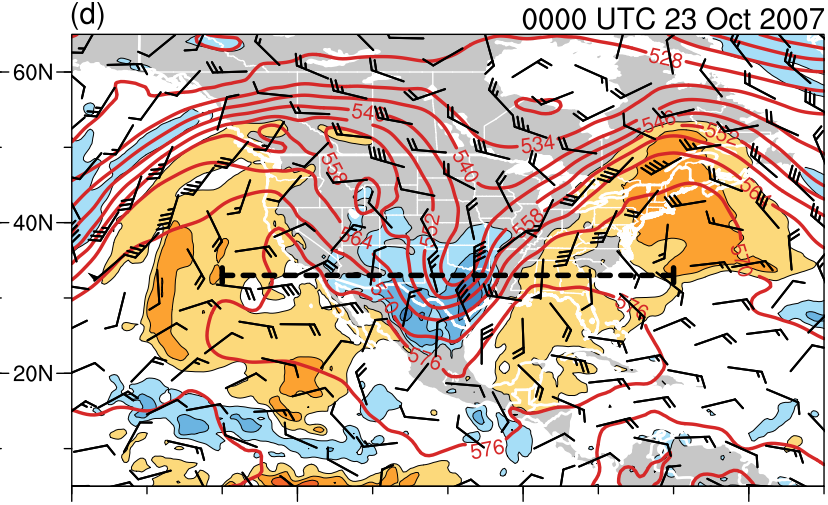

(f)

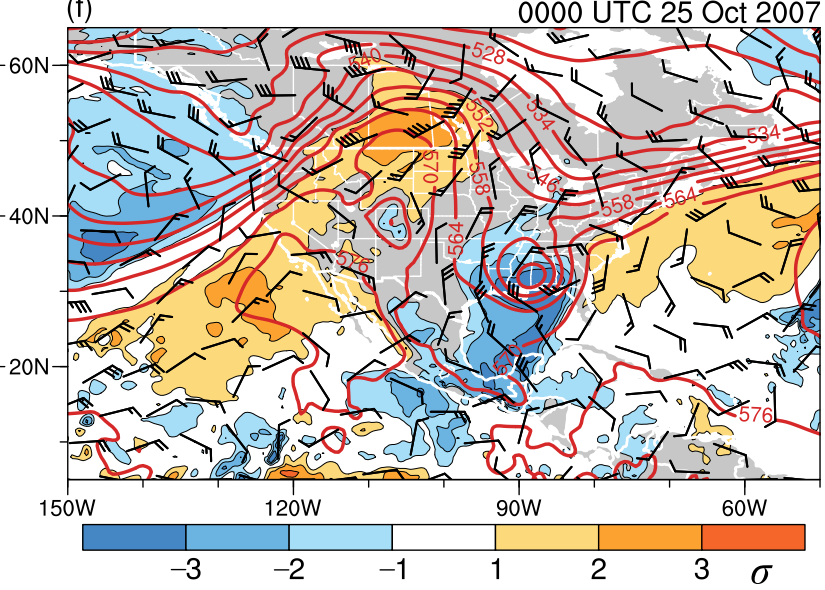

FIG. 16. (left) The 850-hPa geopotential height (contoured in black every 5 dam), precipitable water (shaded in mm according to the color bar), the 2-PVU contour on the 330-K surface (blue), and 1000-300-hPa vertically integrated water vapor transport vectors [plotted for magnitudes $\geq 250 \mathrm{~kg} \mathrm{~m}^{-1} \mathrm{~s}^{-1}$, reference vector in (e)] from the CFSR at (a) 0000 UTC 21 Oct, (c) 0000 UTC 23 Oct, and (e) 0000 UTC 25 Oct 2007. (right) The 1000-500-hPa thickness (contoured in red every 6 dam), 850-hPa normalized temperature anomaly relative to the 1979-2009 climatology (shaded in standard deviations according to the color bar), and 850-hPa wind (plotted for magnitudes $\geq 5 \mathrm{~m} \mathrm{~s}{ }^{-1}$; barbs according to the convention in Fig. 1) from the CFSR at (b) 0000 UTC 21 Oct, (d) 0000 UTC 23 Oct, and (f) 0000 UTC 25 Oct 2007. The dashed black lines in (c),(d) indicate the position of the cross section in Fig. 17.

$\sim 900 \mathrm{hPa}$ (Fig. 19c), warming $\sim 37 \mathrm{~K}$ (Fig. 19g), and exhibiting a decrease in relative humidity to $\sim 10 \%$ (Fig. 19f).

The cold surge air parcels, that originated in the midtroposphere $(\sim 650 \mathrm{hPa})$ over the midlatitude North Pacific, initially ascended and cooled (Figs. 19a,c,g) while moving eastward through the western North America ridge. Between -72 and $0 \mathrm{~h}$ they moved rapidly equatorward east of the Rockies into Mexico (Fig. 19a) in conjunction with strong equatorward flow and cold-air advection (Figs. 16b,d,f). While moving equatorward, the parcels gradually descended isentropically to 


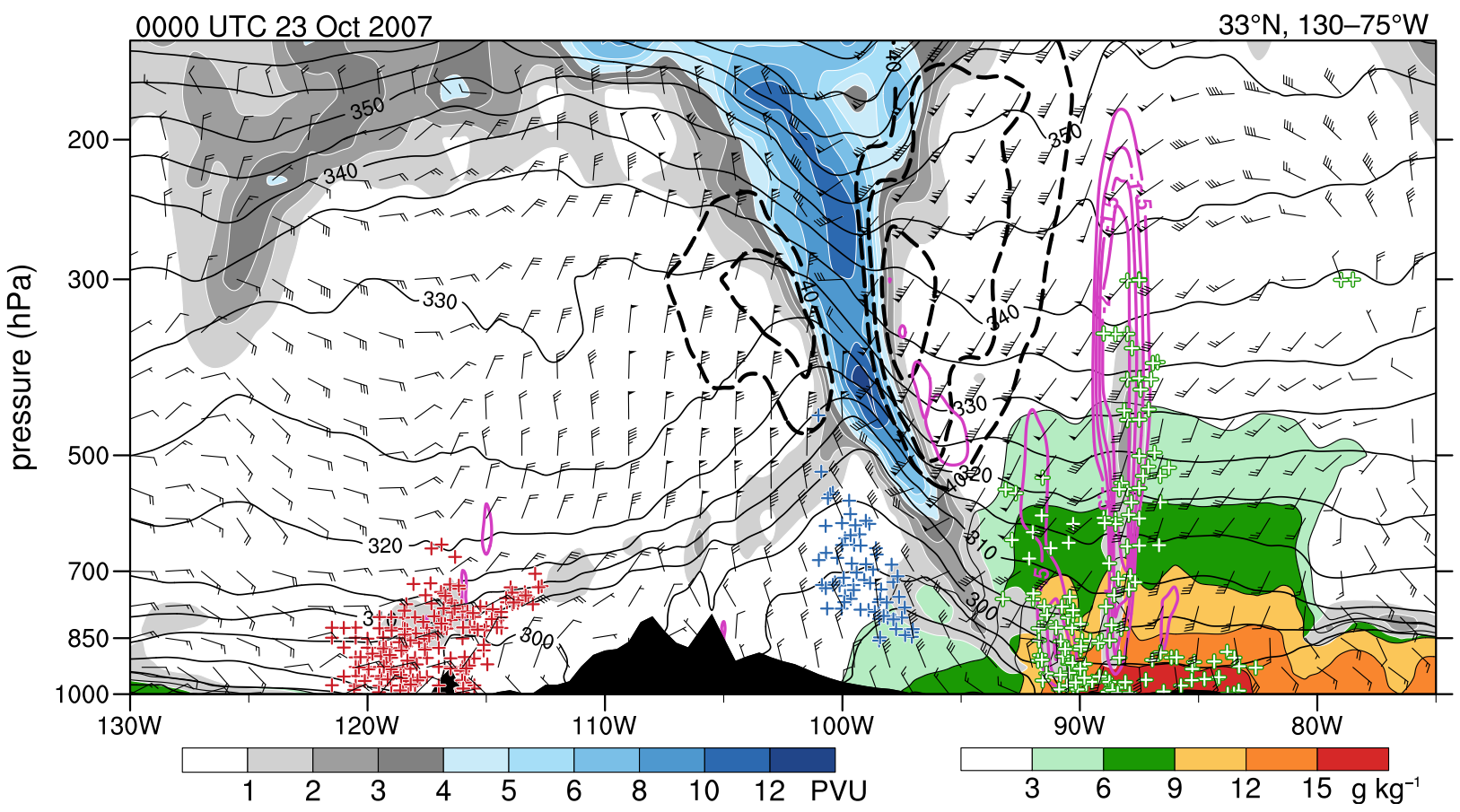

FIG. 17. As in Fig. 11, but for a zonal cross section at 0000 UTC 23 Oct 2007 from $130^{\circ} \mathrm{E}$ to $75^{\circ} \mathrm{W}$ along $33^{\circ} \mathrm{N}$. Intersection points for trajectories shown in Fig. 19a with the cross section at 0000 UTC 23 Oct are marked with the red, blue, and green plus symbols. To improve readability, $25 \%$ of the intersecting trajectories in each group were randomly selected and plotted.

$\sim 900 \mathrm{hPa}$ and warmed, exhibiting little change in $q, \theta$, and relative humidity until after $-24 \mathrm{~h}$ (Figs. $19 \mathrm{~d}-\mathrm{g}$ ).

The air parcels associated with the eastern U.S. heavy rainfall originated in the moist $\left(q\right.$ of $\sim 13 \mathrm{~g} \mathrm{~kg}^{-1}$; Fig. 19d) lower troposphere ( $\sim 850 \mathrm{hPa}$; Fig. $19 \mathrm{c})$ over the Caribbean Sea and the Gulf of Mexico and between -96 and $-24 \mathrm{~h}$ moved poleward across the Gulf of Mexico along anticycloncally curved trajectories (Fig. 19a) on the western flank of an anticyclone centered over the western North Atlantic (Figs. 16c,e), gradually descending and moistening (Figs. 19c,d,f). As they entered the heavy rainfall region downstream of the PV streamer during $-24-0 \mathrm{~h}$, the parcels were forced to ascend abruptly from $\sim 900$ to $\sim 600 \mathrm{hPa}$ (Fig. 19c) and exhibited sharp decreases in $q$ and temperature (Figs. 19d,g) and sharp increases in $\theta$ and relative humidity (Figs. 19e,f), signifying precipitation generation.

\section{Second cold surge and Mexican heavy rainfall}

\section{a. Flow evolution over North America during 26-29 October 2007}

Anticyclonic wave breaking over North America between 21 and 25 October culminated in the transformation of the PV streamer associated with polar disturbance P3 into a cutoff cyclone by 1200 UTC 26 October (Fig. 20a). This cutoff supported moisture transport and heavy precipitation in the southeastern United States (Fig. 20b). During 2628 October, a second episode of ridge amplification and anticyclonic wave breaking occurred over western North America (Figs. 20a,c) as a trough-ridge couplet originally associated with polar disturbance P1 propagated into the eastern North Pacific (Fig. 8b). This episode coincided with the formation of a trough across the Great Lakes that interacted and merged with the cutoff (Fig. 20c), resulting in cyclogenesis over northeastern North America (Fig. 20d). The cyclogenesis coincided with cold-air advection and surface anticyclogenesis over the central United States, corresponding to the second cold surge, evident in the 1000-500-hPa thickness field (Fig. 20d). During 28-29 October as the heavy rainfall in southern Mexico commenced, anticyclonic wave breaking continued (Figs. 20c,e), and the cold surge and associated anticyclone expanded into the Gulf of Mexico, establishing a southwest-northeast-elongated baroclinic zone at the leading edge of the cold surge (Figs. 20d,f). By 1200 UTC 29 October, inferred confluent northeasterly geostrophic surface flow extended across the Gulf of Mexico between the anticyclone and a diffuse low pressure area over the Caribbean Sea (Fig. 20f). An area of PW values $>45 \mathrm{~mm}$ moved into the heavy rainfall region of southern Mexico along this surface northeasterly flow (Fig. 20f). The cool 
(a) 1000-500-hPa thickness continuity: $21-25$ Oct 2007

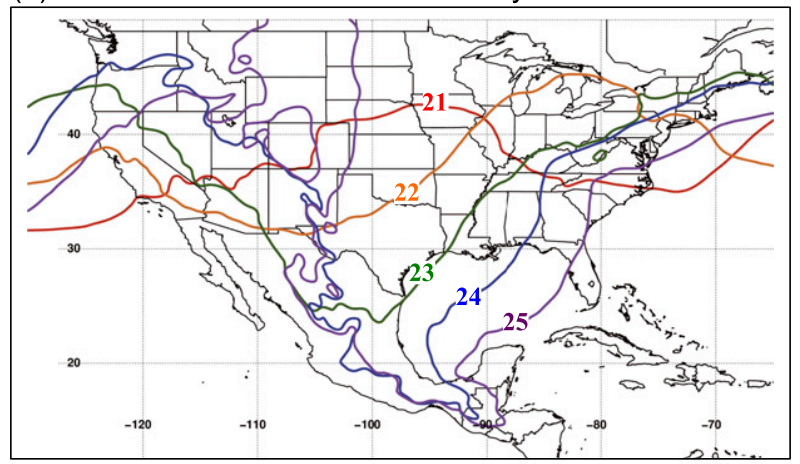

(b) 1000-500-hPa thickness continuity: 26-30 Oct 2007

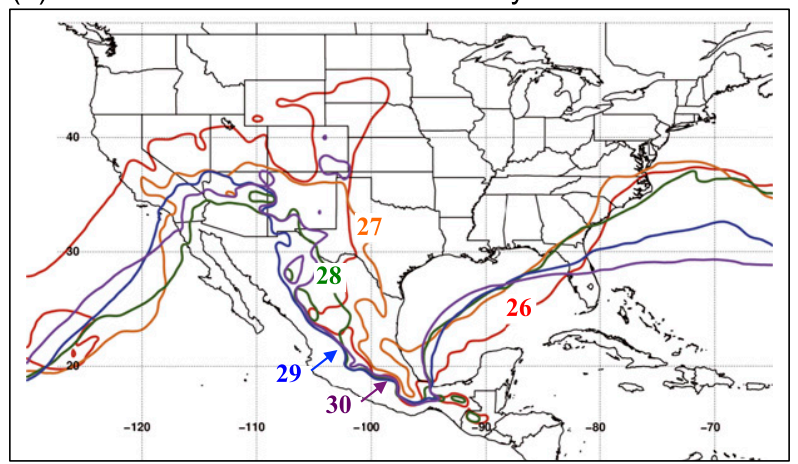

FIG. 18. Continuity charts for the 572-dam contour of 1000-500hPa thickness at 0000 UTC (a) 21-25 Oct and (b) 26-30 Oct 2007 from the CFSR.

conditions persisted across eastern and southern Mexico during 26-30 October in connection with the second cold surge (Fig. 18b).

Between 27 and 29 October, a corridor of strong confluent northeasterly 850 -hPa flow and water vapor transport formed and curved cyclonically across the Gulf of Mexico into the heavy rainfall region over Chiapas and Tabasco, coinciding with the southwestward movement of an area of PW values $>45 \mathrm{~mm}$ (Fig. 21). This process was associated with increasing 850-hPa geopotential height across the Gulf of Mexico linked to the cold surge, and decreasing $850-\mathrm{hPa}$ geopotential height over the Caribbean Sea that coincided with the formation of TC Noel south of Hispaniola (Figs. 21b,d,f). By 1200 UTC 29 October, strong northerly water vapor transport extended into Chiapas and Tabasco (Fig. 21f) approximately perpendicular to the elevated terrain near the border between the two states, supporting heavy orographic rainfall. In addition, lowertropospheric warm-air advection was maintained in the northeasterly flow along the periphery of the cold surge over and to the north of the heavy rainfall region (Fig. 21e), possibly contributing to dynamical forcing of ascent supporting the heavy rainfall. This flow pattern on 29 October was maintained through 31 October (see image loops in the online supplemental material), supporting extraordinary rainfall totals.

The formation of the corridor of strong water vapor transport and high PW extending into the heavy rainfall region coincided with the formation and southwestward progression of a conspicuous mesoscale disturbance ("M"; track shown in Fig. 4), characterized by lowertropospheric cyclonic flow and low IR brightness temperatures (Figs. 21a,c,e and 22a-c). Disturbance $\mathrm{M}$ formed near the Florida Keys at $~ 1200$ UTC 27 October along an $850-\mathrm{hPa}$ trough and an associated wind shift (red dashed line in Fig. 21a). On the synoptic scale, M formed in a region of warm-air advection beneath the equatorward entrance region of a $200-\mathrm{hPa}$ jet streak (Figs. 21a and 22a) and was marked by strong irrotational flow in the equatorward jet entrance region (Fig. 22a) corresponding to strong ascent (not shown). The jet streak was established in connection with a trailing PV filament over the northern Gulf of Mexico (green arrow in Figs. 20a,c,e). Between 27 and 29 October, $\mathrm{M}$ developed a well-defined lower-tropospheric relative vorticity maximum, plausibly a signature of PV generation due to latent heat release from heavy rainfall (e.g., Hoskins et al. 1985; Stoelinga 1996), and tracked southwestward (Figs. 22a-c) with the lower-tropospheric flow (Figs. 21a,c,e) into Chiapas and Tabasco. As M approached the Tabasco coast, it likely contributed to the heavy rainfall by locally enhancing water vapor transport and lifting. Further analysis of $\mathrm{M}$ is beyond the scope of this paper.

\section{b. Lagrangian perspective}

The transport of moist air supporting the heavy rainfall in Chiapas and Tabasco is investigated through 96-h backward HYSPLIT air parcel trajectories released every $6 \mathrm{~h}$ between 0000 UTC 29 and 0000 UTC 30 October from grid points below $300 \mathrm{hPa}$ with $>90 \%$ relative humidity within a box over the heavy rainfall region. Trajectories were required to exhibit a $>5 \mathrm{~g} \mathrm{~kg}^{-1}$ decrease in $q$ in the final $24 \mathrm{~h}$. The trajectories comprised two distinct groups, which originated over the southeastern United States and over the Caribbean Sea and the western North Atlantic, respectively (Fig. 19b). The air parcels extended westward and equatorward across the Gulf of Mexico (Fig. 19b) through confluent northeasterly flow linked to the second cold surge (e.g., Fig. 21c). Between -96 and $-24 \mathrm{~h}$, the parcels generally remained below $850 \mathrm{hPa}$ (Fig. 19c), gradually descended, and exhibited increases in $q$ from $\sim 6$ to $\sim 13 \mathrm{~g} \mathrm{~kg}^{-1}$ (Fig. 19d) and relative humidity from $\sim 70 \%$ to $\sim 90 \%$ (Fig. 19f). During $-24-0 \mathrm{~h}$, the air parcels tracked equatorward into the 
(a) trajectories released $23-24$ Oct 2007

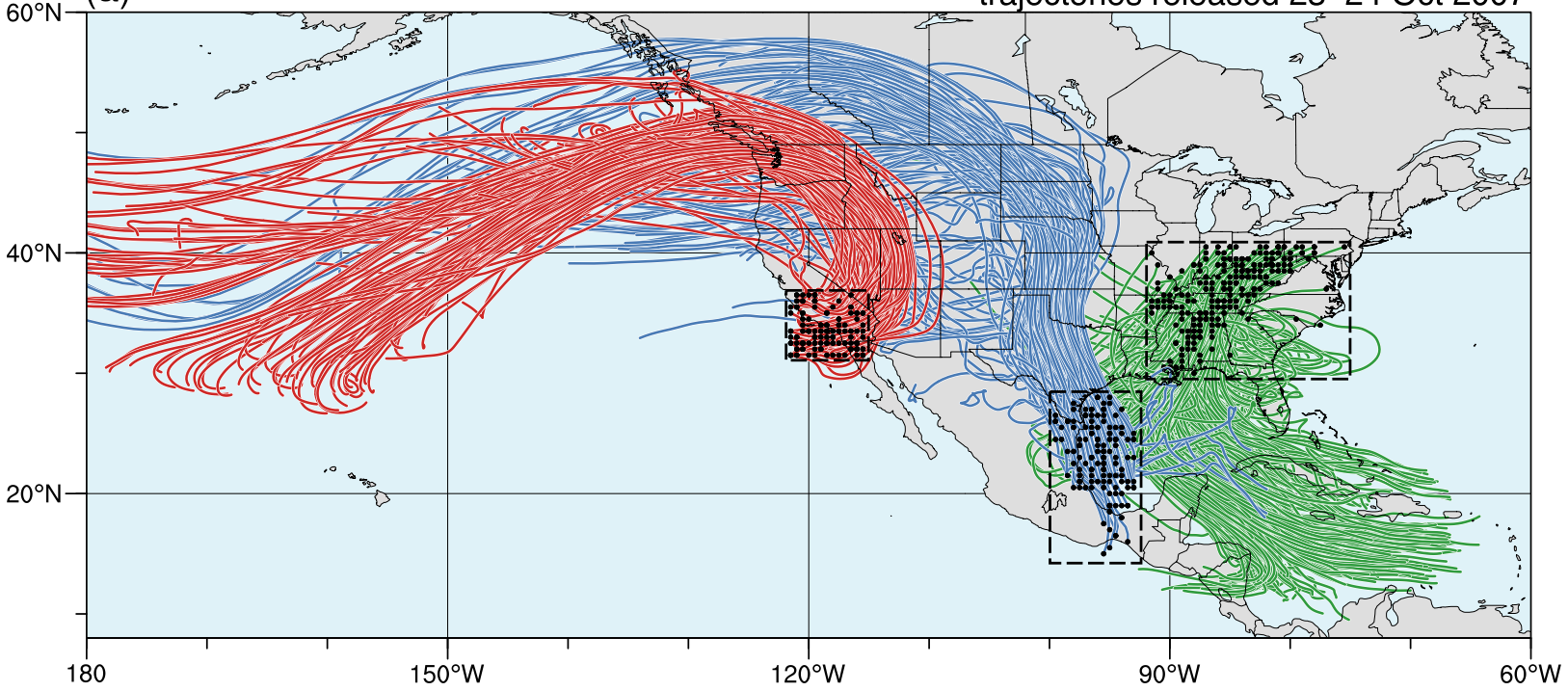

(b) trajectories released $29-30$ Oct 2007
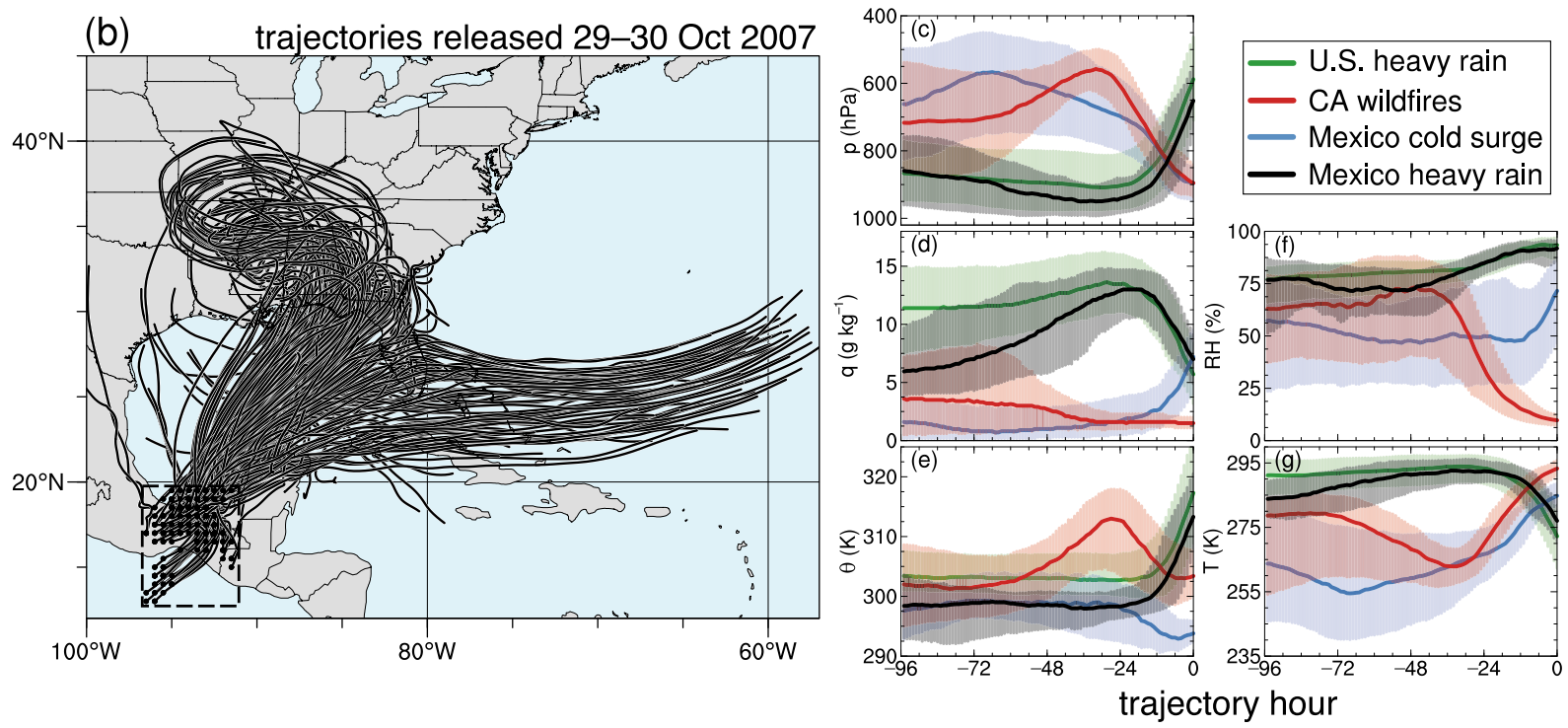

FIG. 19. CFSR-based 96-h backward HYSPLIT trajectories corresponding to the four extreme weather events. (a) Trajectories released every $6 \mathrm{~h}$ between 0000 UTC 23 Oct and 0000 UTC 24 Oct 2007. See text for details of trajectory calculations. To improve readability, $5 \%$ of the trajectories in each group were randomly selected and plotted in (a). (b) Trajectories released every $6 \mathrm{~h}$ between $0000 \mathrm{UTC} 29$ Oct and 0000 UTC 30 Oct 2007. See text for details of trajectory calculations. To improve readability, $25 \%$ of the trajectories in each group were randomly selected and plotted. The release locations of the trajectories in (a),(b) are marked by the black dots. Time series of (c) pressure $(\mathrm{hPa}),(\mathrm{d})$ specific humidity $\left(\mathrm{g} \mathrm{kg}^{-1}\right)$, (e) potential temperature $(\mathrm{K})$, (f) relative humidity $(\%)$, and $(\mathrm{g})$ temperature $(\mathrm{K})$ along the trajectories are displayed as in Fig. 15.

heavy rainfall region (Fig. 19b), ascended $\sim 350 \mathrm{hPa}$ (Fig. 19c), and exhibited a $\sim 5 \mathrm{~g} \mathrm{~kg}^{-1} q$ decrease (Fig. 19d) and a $\sim 16-\mathrm{K} \theta$ increase (Fig. 19e), signifying precipitation. Examination of trajectories ending at 1200 UTC 29 October in relation to the evolution of the $850-\mathrm{hPa}$ geopotential height, vertically integrated water vapor transport, and PW fields (Figs. 21b,d,f) demonstrates confluence and southwestward progression of the air parcels in conjunction with the formation of the strong water vapor transport and high PW extending into the heavy rainfall region.

\section{Summary and conclusions}

This paper has documented key multiscale processes that culminated in four interrelated EWEs over North America-wildfires in Southern California, prolonged anomalous cold conditions in northern and 
(a)

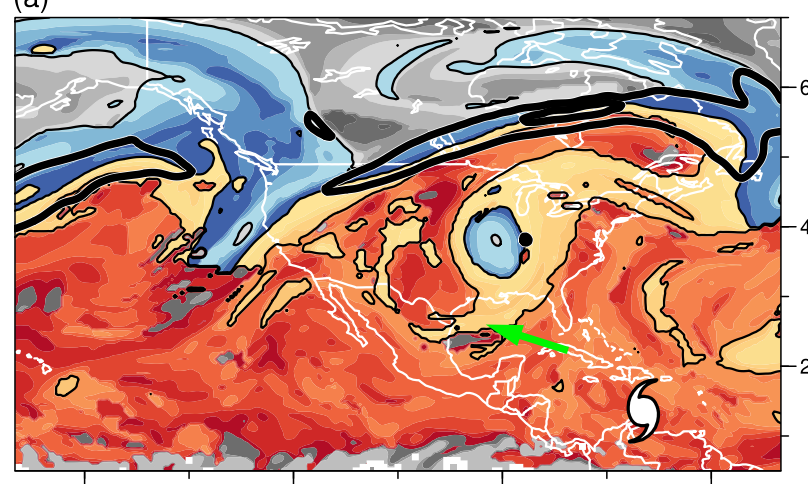

(c)

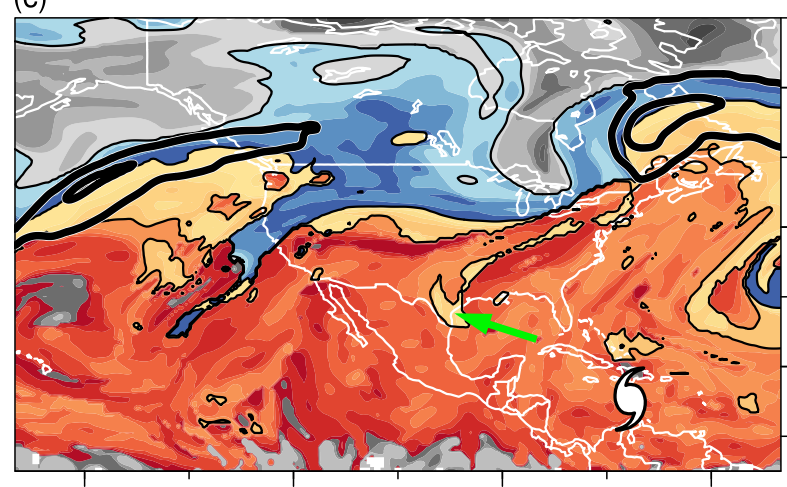

(e)

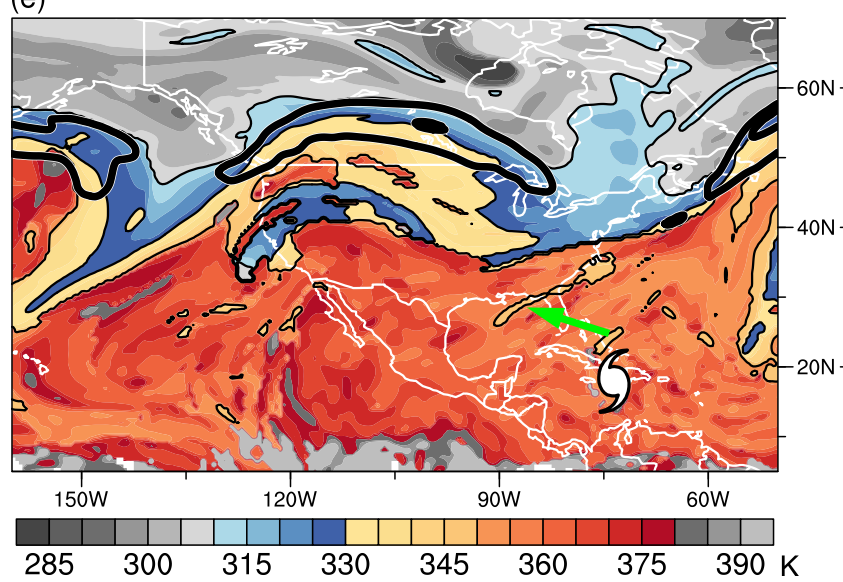

(b)

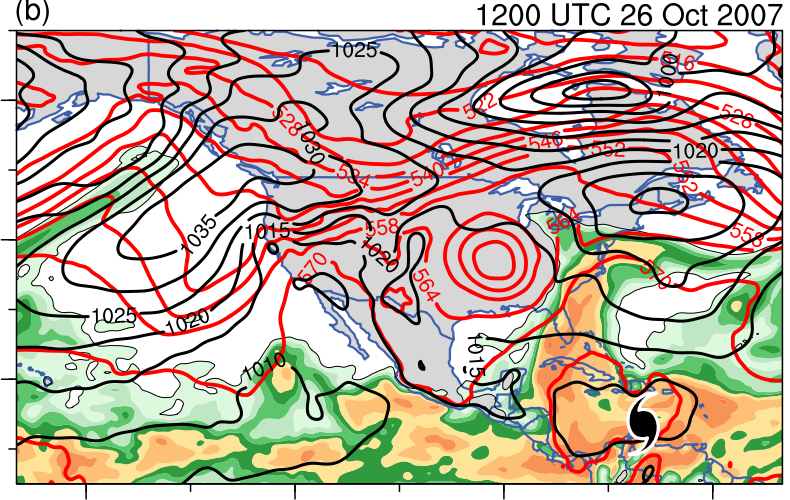

(d)

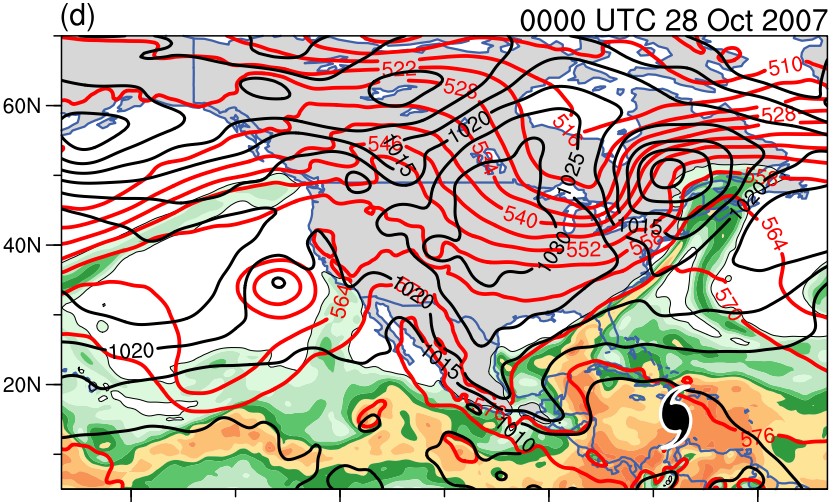

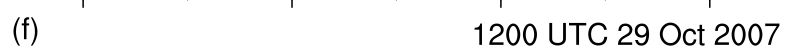

(f)

1200 UTC 29 Oct 2007

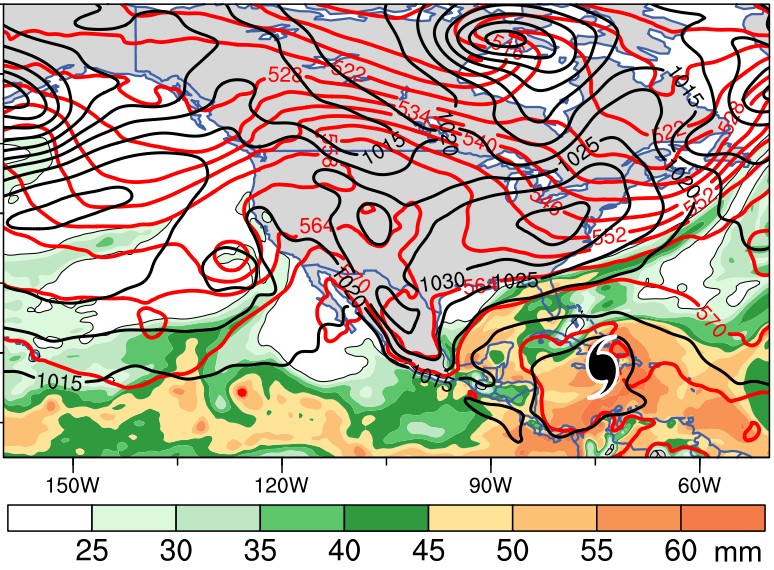

FIG. 20. (left) As in Fig. 9, but for (a) 1200 UTC 26 Oct, (c) 0000 UTC 28 Oct, and (e) 1200 UTC 29 Oct 2007. The green arrow in (a),(c), and (e) points to a trailing PV filament described in the text. (right) As in Fig. 10, but for (b) 1200 UTC 26 Oct, (d) 0000 UTC 28 Oct, and (f) 1200 UTC 29 Oct 2007 . The 1000-500-hPa thickness is contoured every 6 dam. The location of TC Noel is indicated by the TC symbol.

eastern Mexico linked to two cold surges, heavy rainfall in the eastern United States, and floodproducing heavy rainfall in southern Mexico-during 22-31 October 2007. The EWEs were preceded by a rapid transition from an anomalously strong zonal flow configuration to a highly meridional flow configuration across the North Pacific via the formation of a high-amplitude RWT. This transition involved perturbations to an initially strong zonal NPJ waveguide, which was likely conducive to both baroclinic and barotropic instability, from multiple disturbances across the North Pacific, including polar disturbances, extratropical cyclones, a diabatic Rossby vortex, and TC Kajiki. A novel aspect of this paper is the documentation of how the large-scale flow evolved during and after the transition to a meridional flow configuration to produce multiple geographically separate but dynamically linked EWEs. 
(a)

(b)

1200 UTC 27 Oct 2007
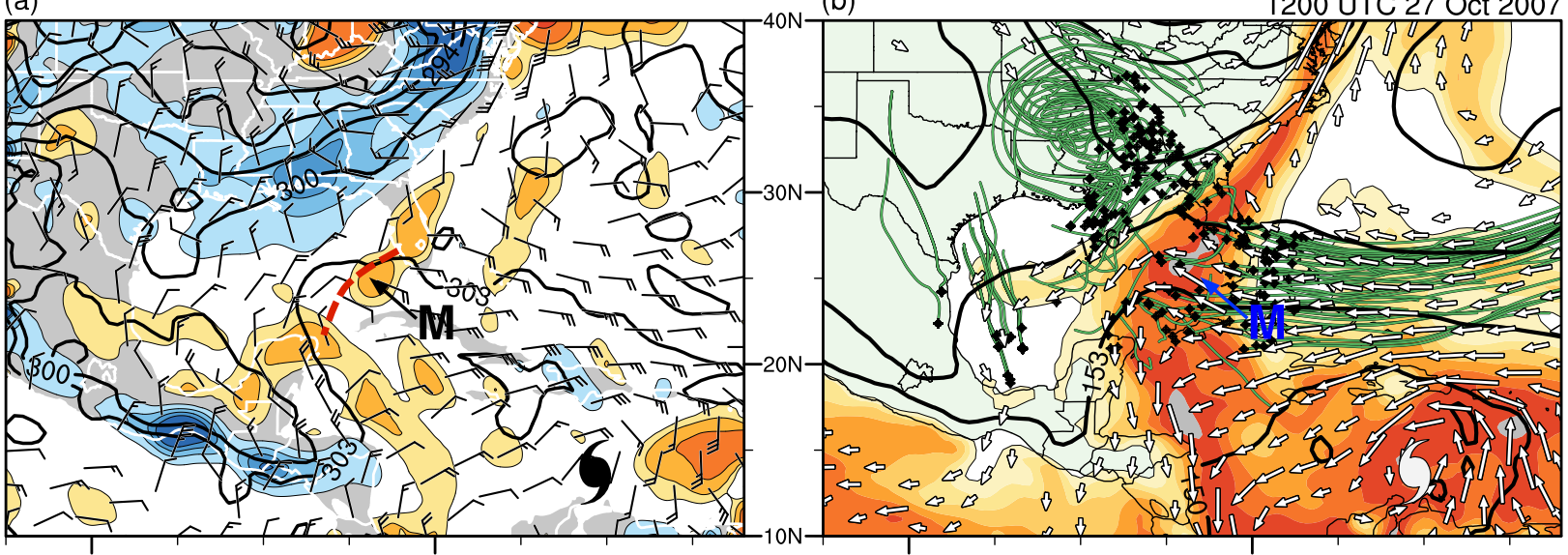

(c)

(d)
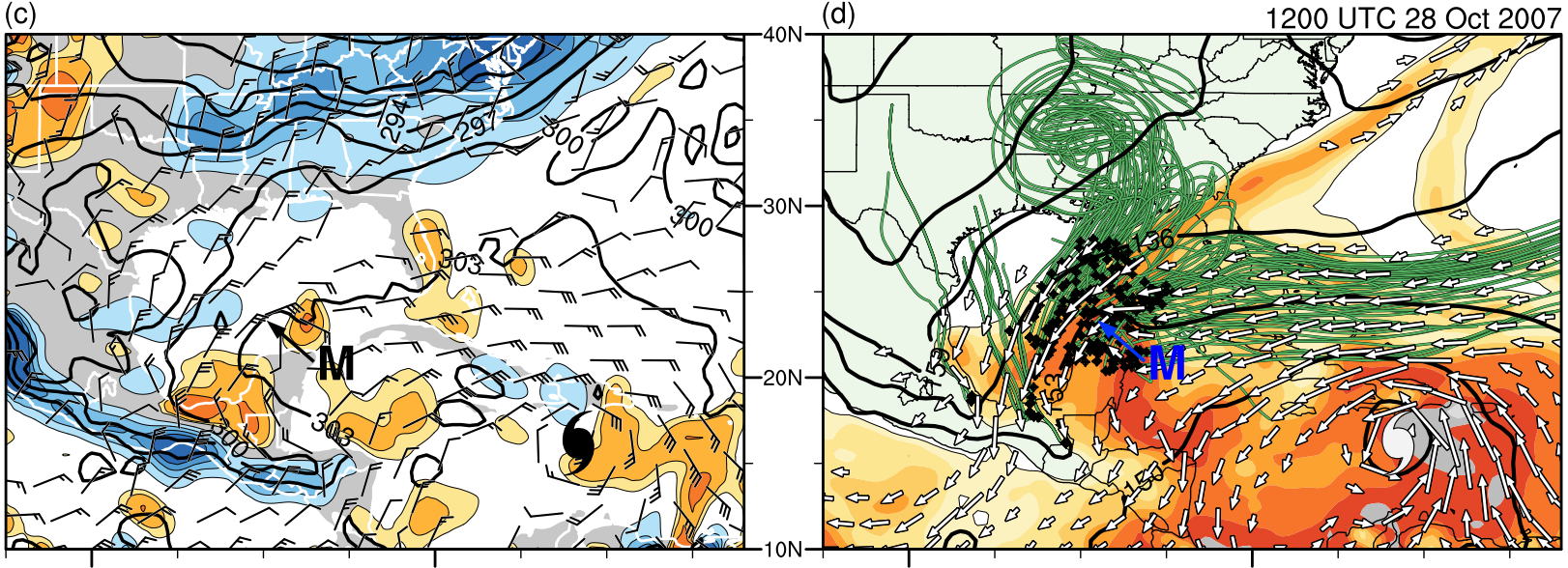

(e)

(f)

1200 UTC 29 Oct 2007
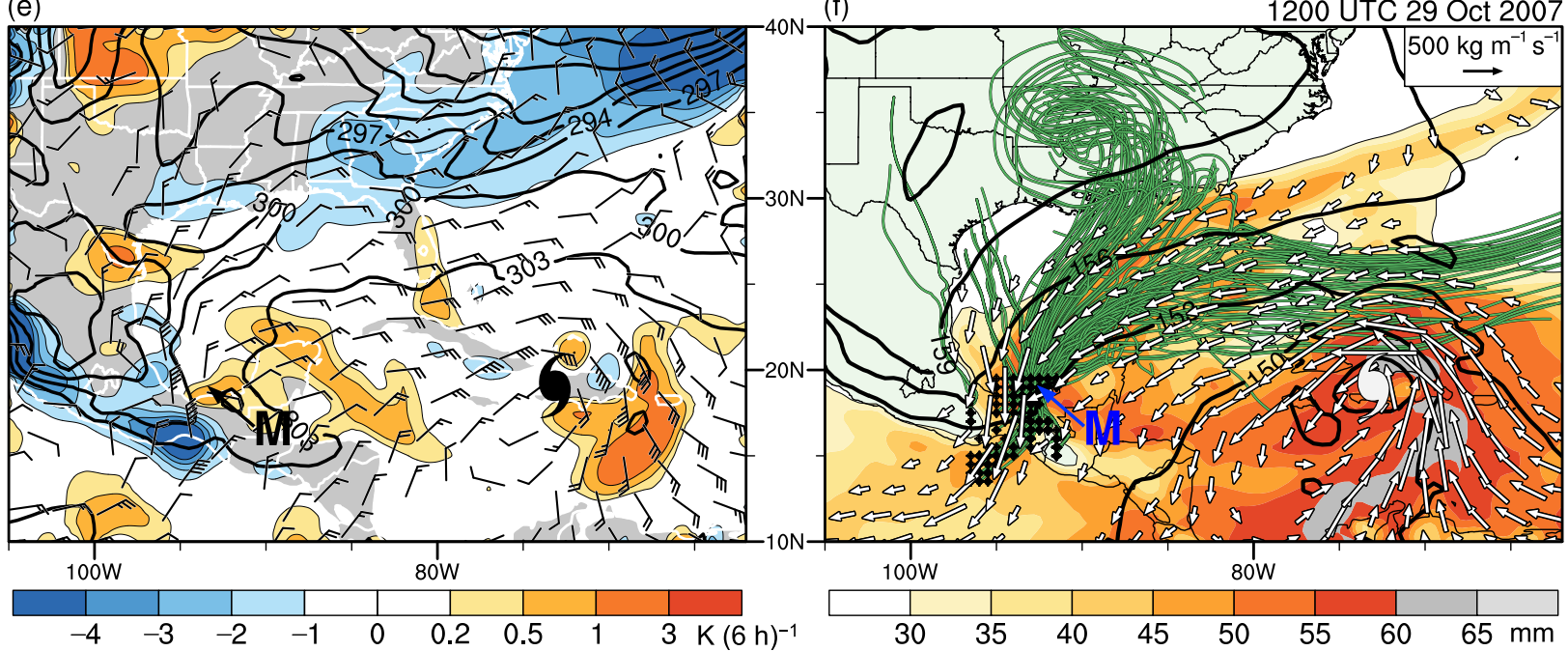

FIG. 21. (left) The 1000-800-hPa layer-averaged potential temperature advection [shaded in $\mathrm{K}(6 \mathrm{~h})^{-1}$ according to the color bar], 850 -hPa potential temperature (contoured in black every $3 \mathrm{~K}$ ), and $850-\mathrm{hPa}$ wind (plotted for magnitudes $\geq 5 \mathrm{~m} \mathrm{~s}^{-1}$; barbs according to the convention in Fig. 1) from the CFSR at (a) 1200 UTC 27 Oct, (c) 1200 UTC 28 Oct, and (e) 1200 UTC 29 Oct 2007. (right) The 850-hPa geopotential height (contoured in black every $5 \mathrm{dam}$ ), precipitable water (shaded in $\mathrm{mm}$ according to the color bar), and 1000-300-hPa vertically integrated water vapor transport vectors [plotted for magnitudes $\geq 250 \mathrm{~kg} \mathrm{~m}^{-1} \mathrm{~s}^{-1}$, reference vector in (f)] from the CFSR at (b) 1200 UTC 27 Oct, (d) 1200 UTC 28 Oct, and (f) 1200 UTC 29 Oct 2007. The evolution of backward trajectories from Fig. 19b that were released at 1200 UTC 29 Oct are shown in (b),(d), and (f). The trajectories are plotted from 1200 UTC 26 Oct to the analysis time, with black plus symbols marking the locations of the trajectories at the analysis time. In all panels, the location of TC Noel is indicated by the TC symbol, and the mesoscale disturbance described in the text is labeled as M. The red dashed line in (a) denotes the position of an 850-hPa trough and the associated wind shift described in the text. 

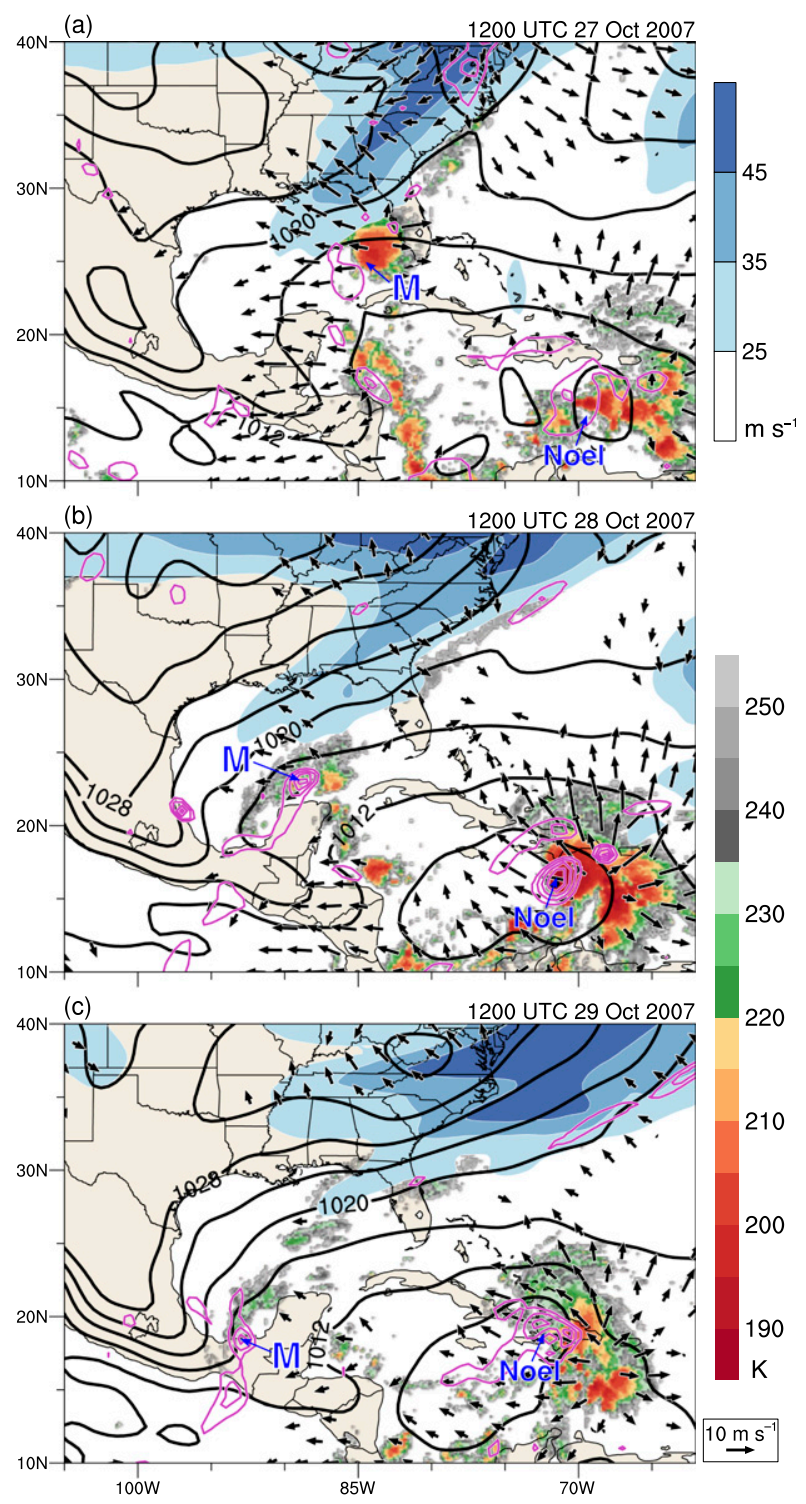

FIG. 22. Infrared brightness temperature from the NASA Gridsat dataset (shaded in $\mathrm{K}$ according to the lower color bar) and 200-hPa wind speed (shaded in $\mathrm{m} \mathrm{s}^{-1}$ according to the upper color bar), 200-hPa irrotational wind vectors $\left(\mathrm{m} \mathrm{s}^{-1}\right.$; reference vector in lower right), sea level pressure (contoured in black every $4 \mathrm{hPa}$ ), and $1000-800-\mathrm{hPa}$ layer-averaged relative vorticity (contoured in magenta every $6 \times 10^{-5} \mathrm{~s}^{-1}$ starting at $6 \times 10^{-5} \mathrm{~s}^{-1}$ ) from the CFSR at 1200 UTC (a) 27 Oct, (b) 28 Oct, and (c) 29 Oct 2007. The mesoscale disturbance (M) described in the text and TC Noel are labeled in blue.

The synoptic-scale conditions supporting the EWEs were found to be a manifestation of pronounced Rossby wave breaking over North America. This finding underscores Rossby wave breaking as a key dynamical pathway for the occurrence not only of individual EWEs but also of multiple linked EWEs. Consonantly, recent studies have documented the role of Rossby wave breaking in linked heat waves and heavy rainfall over Eurasia (Galarneau et al. 2012) and Australia (Parker et al. 2014).

The California wildfires, the first of two cold surges into Mexico, and the eastern U.S. heavy rainfall occurred during 22-26 October in conjunction with anticyclonic wave breaking linked to strong, persistent ridge amplification over western North America and the downstream formation of a meridionally elongated, slow-moving PV streamer. The placement, the large amplitude, and the slow phase speed of the resulting wave pattern were critical for establishing and maintaining conditions supporting the EWEs. For the wildfires, strong lower-tropospheric anticyclogenesis over the U.S. Great Basin associated with the western North American ridge amplification was linked to Santa Ana winds over Southern California. Air parcels entering the wildfire region, originating over the North Pacific, moved through the region of ridge amplification and anticyclogenesis and experienced strong subsidence, warming, and drying. Locally strong warming and drying due to local terrain effects (e.g., Small 1995; Raphael 2003; Huang et al. 2009; Hughes and Hall 2010) not captured in the current study likely also occurred over Southern California.

For the first cold surge, strong northerly flow on the eastern flank of the Great Basin anticyclone forced equatorward advection of cold air east of the Rocky Mountains into Mexico. The cold surge was directly linked to the transformation of polar disturbance P3 into a meridionally elongated upper-level PV streamer over the central United States. This finding is consistent with Sprenger et al. (2013), which indicated a link between PV streamer formation and cold surges in South America. The PV streamer and cold surge were upperand lower-level manifestations of a marked tropospheredeep tropopause fold and frontal zone associated with a superposition of the polar and subtropical jets on the periphery of the western North American ridge.

Consistent with prior studies of PV streamer-related heavy precipitation events (e.g., Massacand et al. 1998; Martius et al. 2006), the PV streamer in this case supported heavy rainfall over the eastern United States. The streamer moved slowly eastward and facilitated a relatively persistent and meridionally elongated corridor of poleward water vapor transport that, as demonstrated by trajectory analysis, enabled sustained transport of moist air originating over the Caribbean Sea and the Gulf of Mexico into the heavy rainfall region. Prior studies have similarly shown the Gulf of Mexico and Caribbean Sea to be key moisture source regions for heavy rainfall events in the central and eastern United States (e.g., 
Dirmeyer and Kinter 2010; Moore et al. 2012; Steinschneider and Lall 2015).

A second anticyclonic wave breaking episode between 26 and 29 October was associated with a second reinforcing cold surge into Mexico, which helped to establish a baroclinic zone and a persistent corridor of confluent lower-tropospheric northeasterly flow across the Gulf of Mexico. Moist air transported through this corridor and entering a region of orographic forcing and lower-tropospheric warm-air advection along the baroclinic zone supported heavy rainfall in Chiapas and Tabasco, Mexico.

The flow amplification that culminated in the EWEs was initiated as tropopause-level polar disturbances P1, P2, and P3 moved equatorward from high latitudes and perturbed and interacted with the NPJ. The flow amplified in conjunction with strong baroclinic development and latent heating linked to poleward moisture transports as polar disturbances $\mathrm{P} 1$ and $\mathrm{P} 2$ interacted with moist lower-latitude disturbances over the North Pacific (TC Kajiki and a diabatic Rossby vortex, respectively). The interaction of the polar disturbances with the NPJ and the associated flow amplification could be viewed as a superposition of and interaction between the polar and subtropical jet streams (e.g., Shapiro et al. 1999; Martius et al. 2010; Winters and Martin 2014; Handlos and Martin 2016). It is conceivable that the polar disturbances were linked to an Arctic jet stream as described by Shapiro et al. (1987) and thereby that a threefold interaction between Arctic, polar, and subtropical jet streams occurred along the amplifying NPJ. Future research on interactions of multiple jet streams for this case and other similar EWE cases is encouraged.

Polar disturbances $\mathrm{P} 1$ and $\mathrm{P} 2$ induced cyclogenesis and strong upper-tropospheric ridge amplification over the western and eastern North Pacific, respectively. Poleward-directed plumes of moisture and associated regions of clouds, precipitation, and upper-level divergent outflow formed downstream of the two disturbances, with negative PV advection by the divergent outflow contributing to ridge amplification. The moisture plumes were related to WCBs extending poleward from low latitudes into the NPJ over the western and eastern Pacific. Consistent with prior studies (e.g., Grams et al. 2011; Sodemann and Stohl 2013; Madonna et al. 2014b; Pfahl et al. 2014; Grams and Archambault 2016), the WCB air parcels originated in the moist tropical and subtropical boundary layer, underwent deep ascent, condensation, and latent heating, contributing to ridge amplification. Moist air parcels in the western North Pacific WCB originated within a plume of water vapor in the immediate vicinity of TC Kajiki, suggesting that the precipitation along the WCB may have been associated with a "predecessor rain event" (e.g., Galarneau et al. 2010; Bosart et al. 2012; Moore et al. 2013). The WCB served as a mechanism whereby TC Kajiki remotely influenced the amplification of the NPJ without directly interacting with the NPJ (e.g., Archambault et al. 2013). Prior studies (Cordeira et al. 2013; Grams and Archambault 2016) have documented similar remote influences of TCs on the NPJ.

The ridge amplification associated with polar disturbance P1 induced downstream baroclinic development, manifested by eastern North Pacific trough amplification and secondary surface cyclogenesis immediately upstream of polar disturbance P2, helping to reinforce and amplify the ridge that had already developed in connection with P2 over the eastern North Pacific and western North America. Consequently, the ridge amplified, expanded zonally, and slowed its eastward translation, coinciding with the elongation and slowing of the downstream PV streamer. This process, manifested as anticyclonic wave breaking, established a high-amplitude, slow-moving wave pattern across North America supporting the EWEs.

We conclude by highlighting future research directions motivated by the current study. Future research could investigate whether cases of multiple EWEs tend to result, as in the current study, from significant large-scale flow amplification involving strong baroclinic and diabatic (latent heating) influences due to interactions between high-latitude baroclinic disturbances and warm, moist midlatitude or tropical disturbances. Furthermore, future research could assess the seasonal and geographical variability of this type of flow amplification scenario. In this regard, we hypothesize that during autumn the NPJ may be particularly conducive to large-scale flow amplification, potentially resulting in EWEs. Specifically, increases in snow cover and the concomitant build-up of cold air in autumn over northeastern Asia, which juts east to the date line poleward of the western North Pacific oceanic warm pool, may result in a strengthening NPJ waveguide that is increasingly conducive to downstream baroclinic development. In addition, increasing snow cover over northeastern Asia may enable polar disturbances to maintain their strength to the longitudes of the strengthening NPJ. If extracted into midlatitudes at those longitudes, these disturbances can then strongly perturb the NPJ and interact with moist lower-latitude disturbances, potentially inducing significant large-scale flow amplification. Research aimed at testing these hypotheses regarding the autumnal North Pacific is encouraged. 
Acknowledgments. The authors thank Thomas Galarneau (University of Arizona) for his insights on the case documented in this paper, Alan Brammer (University at Albany) for providing the CFSR data and the HYSPLIT trajectory code, and four anonymous reviewers for their constructive comments. Support was provided by NSF Awards AGS- 1355960 and AGS0935830, and NOAA Award NA15NWS4680006.

\section{REFERENCES}

Abatzoglou, J. T., R. Barbero, and N. J. Nauslar, 2013: Diagnosing Santa Ana winds in Southern California with synoptic-scale analysis. Wea. Forecasting, 28, 704-710, doi:10.1175/ WAF-D-13-00002.1.

Agusti-Panareda, A., C. D. Thorncroft, G. C. Craig, and S. L. Gray, 2004: The extratropical transition of Hurricane Irene (1999): A potential-vorticity perspective. Quart. J. Roy. Meteor. Soc., 130, 1047-1074, doi:10.1256/qj.02.140.

Aiyyer, A., 2015: Recurving western North Pacific tropical cyclones and midlatitude predictability. Geophys. Res. Lett., $\mathbf{4 2}$, 7799-7807, doi:10.1002/2015GL065082.

Anwender, D., P. A. Harr, and S. C. Jones, 2008: Predictability associated with the downstream impacts of the extratropical transition of tropical cyclones: Case studies. Mon. Wea. Rev., 136, 3226-3247, doi:10.1175/2008MWR2249.1.

Aparicio, J., P. F. Martínez-Austria, A. Güitrón, and A. I. Ramírez, 2009: Floods in Tabasco, Mexico: A diagnosis and proposal for courses of action. J. Flood Risk Manage., 2, 132-138, doi:10.1111/j.1753-318X.2009.01026.x.

Appenzeller, C., and H. C. Davies, 1992: Structure of stratospheric intrusions into the troposphere. Nature, 358, 570-572, doi:10.1038/358570a0.

Archambault, H. M., L. F. Bosart, D. Keyser, and J. M. Cordeira, 2013: A climatological analysis of the extratropical flow response to recurving western North Pacific tropical cyclones. Mon. Wea. Rev., 141, 2325-2346, doi:10.1175/ MWR-D-12-00257.1.

, D. Keyser, L. F. Bosart, C. A. Davis, and J. M. Cordeira, 2015: A composite perspective of the extratropical flow response to recurving western North Pacific tropical cyclones. Mon. Wea. Rev., 143, 1122-1141, doi:10.1175/MWR-D-14-00270.1.

Atallah, E. H., and L. F. Bosart, 2003: The extratropical transition and precipitation distribution of Hurricane Floyd (1999). Mon. Wea. Rev., 131, 1063-1081, doi:10.1175/ 1520-0493(2003)131<1063:TETAPD>2.0.CO;2.

Boettcher, M., and H. Wernli, 2011: Life cycle study of a diabatic Rossby wave as a precursor to rapid cyclogenesis in the North Atlantic-Dynamics and forecast performance. Mon. Wea. Rev., 139, 1861-1878, doi:10.1175/2011MWR3504.1.

$\longrightarrow$, and - 2013: A 10-yr climatology of diabatic Rossby waves in the Northern Hemisphere. Mon. Wea. Rev., 141, 1139-1154, doi:10.1175/MWR-D-12-00012.1.

- and - 2015: Diabatic Rossby waves in the Southern Hemisphere. Quart. J. Roy. Meteor. Soc., 141, 3106-3117, doi:10.1002/qj.2595.

Bosart, L. F., J. M. Cordeira, T. J. Galarneau Jr., B. J. Moore, and H. M. Archambault, 2012: An analysis of multiple predecessor rain events ahead of Tropical Cyclones Ike and Lowell: 10 15 September 2008. Mon. Wea. Rev., 140, 1081-1107, doi:10.1175/MWR-D-11-00163.1.
Brennan, M. J., H. D. Cobb III, and R. D. Knabb, 2010: Observations of Gulf of Tehuantepec gap wind events from QuikSCAT: An updated event climatology and operational model evaluation. Wea. Forecasting, 25, 646-658, doi:10.1175/ 2009WAF2222324.1.

California Department of Forestry and Fire Protection, 2007: California fire siege 2007: An overview. California Department of Forestry and Fire Protection, 109 pp. [Available online at http://www.fire.ca.gov/fire_protection/downloads/ siege/2007/Overview_CompleteFinal.pdf.]

Carlson, T. N., 1980: Airflow through midlatitude cyclones and the comma cloud pattern. Mon. Wea. Rev., 108, 1498-1509, doi:10.1175/1520-0493(1980)108<1498:ATMCAT>2.0.CO;2.

Cavallo, S. M., and G. J. Hakim, 2009: Potential vorticity diagnosis of a tropopause polar cyclone. Mon. Wea. Rev., 137, 13581371, doi:10.1175/2008MWR2670.1.

— and - 2010: Composite structure of tropopause polar cyclones. Mon. Wea. Rev., 138, 3840-3857, doi:10.1175/ 2010MWR3371.1.

— and — 2012: Radiative impact on tropopause polar vortices over the Arctic. Mon. Wea. Rev., 140, 1683-1702, doi:10.1175/MWR-D-11-00182.1.

—, and —, 2013: Physical mechanism of tropopause polar vortex intensity. J. Atmos. Sci., 70, 3359-3373, doi:10.1175/ JAS-D-13-088.1.

Chang, E. K. M., 2005: The impact of wave packets propagating across Asia on Pacific cyclone development. Mon. Wea. Rev., 133, 1998-2015, doi:10.1175/MWR2953.1.

—- and I. Orlanski, 1993: On the dynamics of a storm track. J. Atmos. Sci., 50, 999-1015, doi:10.1175/ 1520-0469(1993)050<0999:OTDOAS $>2.0 . \mathrm{CO} ; 2$

— and D. B. Yu, 1999: Characteristics of wave packets in the upper troposphere. Part I: Northern Hemisphere winter. J. Atmos. Sci., 56, 1708-1728, doi:10.1175/1520-0469(1999)056<1708: COWPIT $>2.0 . \mathrm{CO} ; 2$.

Colle, B. A., and C. F. Mass, 1995: The structure and evolution of cold surges east of the Rocky Mountains. Mon. Wea. Rev., 123, 2577-2610, doi:10.1175/1520-0493(1995)123<2577: TSAEOC $>2.0 . \mathrm{CO} ; 2$.

Cordeira, J. M., and L. F. Bosart, 2010: The antecedent large-scale conditions of the "Perfect Storms" of late October and early November 1991. Mon. Wea. Rev., 138, 2546-2569, doi:10.1175/ 2010MWR3280.1.

_ , F. M. Ralph, and B. J. Moore, 2013: The development and evolution of two atmospheric rivers in proximity to western North Pacific tropical cyclones in October 2010. Mon. Wea. Rev., 141, 4234-4255, doi:10.1175/MWR-D-13-00019.1.

Dickinson, M. J., L. F. Bosart, W. E. Bracken, G. J. Hakim, D. M Schultz, M. A. Bedrick, and K. R. Tyle, 1997: The March 1993 Superstorm cyclogenesis: Incipient phase synoptic- and convective-scale flow interaction and model performance. Mon. Wea. Rev., 125, 3041-3072, doi:10.1175/1520-0493(1997)125<3041: TMSCIP $>2.0 . C O ; 2$.

Dirmeyer, P. A., and J. L. Kinter, 2010: Floods over the U.S. Midwest: A regional water cycle perspective. J. Hydrometeor. 11, 1172-118, doi:10.1175/2010JHM1196.1.

Draxler, R. R., and G. D. Hess, 1998: An overview of the HYSPLIT 4 modeling system of trajectories, dispersion, and deposition. Aust. Meteor. Mag., 47, 295-308.

Enomoto, T., W. Ohfuchi, H. Nakamura, and M. A. Shapiro, 2007: Remote effects of tropical storm Cristobal upon a cut-off cyclone over Europe in August 2002. Meteor. Atmos. Phys., 96, 29-42, doi:10.1007/s00703-006-0219-2. 
Fore, A. G., B. W. Stiles, A. H. Chau, B. A. Williams, R. S. Dunbar, and E. Rodriguez, 2014: Point-wise wind retrieval and ambiguity removal improvements for the QuikSCAT climatological data set. IEEE Trans. Geosci. Remote Sens., 52, 51-59, doi:10.1109/TGRS.2012.2235843.

Galarneau, T. J., L. F. Bosart, and R. S. Schumacher, 2010: Predecessor rain events ahead of tropical cyclones. Mon. Wea. Rev., 138, 3272-3297, doi:10.1175/2010MWR3243.1.

_ , T. M. Hamill, R. M. Dole, and J. Perlwitz, 2012: A multiscale analysis of the extreme weather events over western Russia and northern Pakistan during July 2010. Mon. Wea. Rev., 140, 1639-1664, doi:10.1175/MWR-D-11-00191.1.

Glatt, I., and V. Wirth, 2014: Identifying Rossby wave trains and quantifying their properties. Quart. J. Roy. Meteor. Soc., 140, 384-396, doi:10.1002/qj.2139.

Grams, C. M., and H. M. Archambault, 2016: The key role of diabatic outflow in amplifying the midlatitude flow: A representative case study of weather systems surrounding western North Pacific extratropical transition. Mon. Wea. Rev., 144, 3847-3869, doi:10.1175/MWR-D-15-0419.1.

_ , and S. R. Blumer, 2015: European high-impact weather caused by the downstream response to the extratropical transition of North Atlantic Hurricane Katia (2011). Geophys. Res. Lett., 42, 8738-8748, doi:10.1002/2015GL066253.

__ , and Coauthors, 2011: The key role of diabatic processes in modifying the upper-tropospheric wave guide: A North Atlantic case-study. Quart. J. Roy. Meteor. Soc., 137, 2174-2193, doi:10.1002/qj.891.

- S. C. Jones, C. A. Davis, P. A. Harr, and M. Weissmann, 2013: The impact of Typhoon Jangmi (2008) on the midlatitude flow. Part I: Upper-level ridgebuilding and modification of the jet. Quart. J. Roy. Meteor. Soc., 139, 2148-2164, doi:10.1002/ qj.2091.

_ _ S. T. K. Lang, and J. H. Keller, 2015: A quantitative assessment of the sensitivity of the downstream midlatitude flow response to extratropical transition of tropical cyclones. Geophys. Res. Lett., 42, 9521-9529, doi:10.1002/ 2015 GL065764.

Griffin, K. S., and L. F. Bosart, 2014: The extratropical transition of Tropical Cyclone Edisoana (1990). Mon. Wea. Rev., 142, 2772-2793, doi:10.1175/MWR-D-13-00282.1.

Hakim, G. J., 2003: Developing wave packets in the North Pacific storm track. Mon. Wea. Rev., 131, 2824-2837, doi:10.1175/ 1520-0493(2003)131<2824:DWPITN>2.0.CO;2.

__ , and A. K. Canavan, 2005: Observed cyclone-anticyclone tropopause vortex asymmetries. J. Atmos. Sci., 62, 231-240, doi:10.1175/JAS-3353.1.

Hamill, T. M., G. T. Bates, J. S. Whitaker, D. R. Murray, M. Fiorino, T. J. Galarneau, Y. Zhu, and W. Lapenta, 2013: NOAA's second-generation global medium-range ensemble reforecast dataset. Bull. Amer. Meteor. Soc., 94, 1553-1565, doi:10.1175/BAMS-D-12-00014.1.

Handlos, Z., and J. Martin, 2016: Composite analysis of large-scale environments conducive to West Pacific polar/subtropical jet superposition. J. Climate, 29, 7145-7165, doi:10.1175/ JCLI-D-16-0044.1.

Harr, P. A., and J. M. Dea, 2009: Downstream development associated with the extratropical transition of tropical cyclones over the western North Pacific. Mon. Wea. Rev., 137, 12951319, doi:10.1175/2008MWR2558.1.

_ - D. Anwender, and S. C. Jones, 2008: Predictability associated with the downstream impacts of the extratropical transition of tropical cyclones: Methodology and a case study of Typhoon Nabi (2005). Mon. Wea. Rev., 136, 32053225, doi:10.1175/2008MWR2248.1.

Hart, R. E., and R. H. Grumm, 2001: Using normalized climatological anomalies to rank synoptic-scale events objectively. Mon. Wea. Rev., 129, 2426-2442, doi:10.1175/ 1520-0493(2001)129<2426:UNCATR > 2.0.CO;2.

Hoskins, B. J., M. E. McIntyre, and A. W. Robertson, 1985: On the use and significance of isentropic potential vorticity maps. Quart. J. Roy. Meteor. Soc., 111, 877-946, doi:10.1002/ qj.49711147002.

Huang, C., Y.-L. Lin, M. L. Kaplan, and J. J. Charney, 2009: Synoptic-scale and mesoscale environments conducive to forest fires during the October 2003 extreme fire event in Southern California. J. Appl. Meteor. Climatol., 48, 553579, doi:10.1175/2008JAMC1818.1.

Hughes, M., and A. Hall, 2010: Local and synoptic mechanisms causing Southern California's Santa Ana winds. Climate Dyn., 34, 847-857, doi:10.1007/s00382-009-0650-4.

Jones, S. C., and Coauthors, 2003: The extratropical transition of tropical cyclones: Forecast challenges, current understanding, and future directions. Wea. Forecasting, 18, 1052-1092, doi:10.1175/1520-0434(2003)018<1052: TETOTC $>2.0 . \mathrm{CO} ; 2$.

Keeley, J. E., H. Safford, C. J. Fotheringham, J. Franklin, and M. Moritz, 2009: The 2007 southern California wildfires: Lessons in complexity. J. For., 107, 287-296.

Keller, J. H., S. C. Jones, and P. A. Harr, 2014: An eddy kinetic energy view of physical and dynamical processes in distinct forecast scenarios for the extratropical transition of two tropical cyclones. Mon. Wea. Rev., 142, 2751-2771, doi:10.1175/MWR-D-13-00219.1.

Klein, P. M., P. A. Harr, and R. L. Elsberry, 2000: Extratropical transition of western North Pacific tropical cyclones: An overview and conceptual model of the transformation stage. Wea. Forecasting, 15, 373-395, doi:10.1175/ 1520-0434(2000)015<0373:ETOWNP>2.0.CO;2.

Knapp, K. R., M. C. Kruk, D. H. Levinson, H. J. Diamond, and C. J. Neumann, 2010: The International Best Track Archive for Climate Stewardship (IBTrACS). Bull. Amer. Meteor. Soc., 91, 363-376, doi:10.1175/2009BAMS2755.1.

_ , and Coauthors, 2011: Globally gridded satellite observations for climate studies. Bull. Amer. Meteor. Soc., 92, 893-907, doi:10.1175/2011BAMS3039.1.

Knippertz, P., and J. E. Martin, 2005: Tropical plumes and extreme precipitation in subtropical and tropical West Africa. Quart. J. Roy. Meteor. Soc., 131, 2337-2365, doi:10.1256/qj.04.148.

Lee, S., and I. M. Held, 1993: Baroclinic wave packets in models and observations. J. Atmos. Sci., 50, 1413-1428, doi:10.1175/ 1520-0469(1993)050<1413:BWPIMA $>2.0$. CO;2.

Lin, Y., and K. E. Mitchell, 2005: The NCEP Stage II/IV hourly precipitation analyses: Development and applications. 19th Conf. on Hydrology, San Diego, CA, Amer. Meteor. Soc., 1.2. [Available online at http://ams.confex.com/ams/pdfpapers/ 83847.pdf.]

Lorenz, E. N., 1955: Available potential energy and the maintenance of the general circulation. Tellus, 7A, 157-167, doi:10.1111/j.2153-3490.1955.tb01148.x.

Madonna, E., S. Limbach, C. Aebi, H. Joos, H. Wernli, and O. Martius, 2014a: On the co-occurrence of warm conveyor belt outflows and PV streamers. J. Atmos. Sci., 71, 3668-3673, doi:10.1175/JAS-D-14-0119.1.

, H. Wernli, H. Joos, and O. Martius, 2014b: Warm conveyor belts in the ERA-Interim dataset (1979-2010). Part I: Climatology and 
potential vorticity evolution. J. Climate, 27, 3-26, doi:10.1175/ JCLI-D-12-00720.1.

-, M. Boettcher, C. M. Grams, H. Joos, O. Martius, and H. Wernli, 2015: Verification of North Atlantic warm conveyor belt outflows in ECMWF forecasts. Quart. J. Roy. Meteor. Soc., 141, 1333-1344, doi:10.1002/qj.2442.

Martínez-Alvarado, O., E. Madonna, S. L. Gray, and H. Joos, 2016: A route to systematic error in forecasts of Rossby waves. Quart. J. Roy. Meteor. Soc., 142, 196-210, doi:10.1002/qj.2645.

Martius, O., E. Zenklusen, C. Schwierz, and H. C. Davies, 2006: Episodes of Alpine heavy precipitation with an overlying elongated stratospheric intrusion: A climatology. Int. J. Climatol., 26, 1149-1164, doi:10.1002/joc.1295.

_ C. Schwierz, and H. C. Davies, 2008: Far-upstream precursors of heavy precipitation events on the Alpine south-side. Quart. J. Roy. Meteor. Soc., 134, 417-428, doi:10.1002/qj.229.

- - - and 2010: Tropopause-level waveguides. J. Atmos. Sci., 67, 866-879, doi:10.1175/2009JAS2995.1.

— surface processes for the Pakistan flood of July 2010. Quart. J. Roy. Meteor. Soc., 139, 1780-1797, doi:10.1002/qj.2082.

Massacand, A. C., H. Wernli, and H. C. Davies, 1998: Heavy precipitation on the alpine southside: An upper-level precursor. Geophys. Res. Lett., 25, 1435-1438, doi:10.1029/98GL50869.

,$- \ldots$, and -2001 : Influence of upstream diabatic heating upon an alpine event of heavy precipitation. Mon. Wea. Rev., 129, 2822-2828, doi:10.1175/1520-0493(2001)129<2822: IOUDHU $>2.0 . \mathrm{CO} ; 2$.

McIntyre, M. E., and T. Palmer, 1983: Breaking planetary waves in the stratosphere. Nature, 305, 593-600, doi:10.1038/305593a0. -, and _ 1984: The surf zone in the stratosphere. J. Atmos. Terr. Phys., 46, 825-849, doi:10.1016/0021-9169(84)90063-1.

McTaggart-Cowan, R., L. F. Bosart, J. R. Gyakum, and E. H. Atallah, 2007: Hurricane Katrina (2005). Part II: Evolution and hemispheric impacts of a diabatically generated warm pool. Mon. Wea. Rev., 135, 3927-3949, doi:10.1175/ 2007MWR2096.1.

Moore, B. J., P. J. Neiman, F. M. Ralph, and F. E. Barthold, 2012: Physical processes associated with heavy flooding rainfall in Nashville, Tennessee, and vicinity during 1-2 May 2010: The role of an atmospheric river and mesoscale convective systems. Mon. Wea. Rev., 140, 358-378, doi:10.1175/ MWR-D-11-00126.1.

— L. F. Bosart, D. Keyser, and M. L. Jurewicz, 2013: Synopticscale environments of predecessor rain events occurring east of the Rocky Mountains in association with Atlantic basin tropical cyclones. Mon. Wea. Rev., 141, 1022-1047, doi:10.1175/MWR-D-12-00178.1.

Moore, R. W., and M. T. Montgomery, 2004: Reexamining the dynamics of short-scale, diabatic Rossby waves and their role in midlatitude moist cyclogenesis. J. Atmos. Sci., 61, 754-768, doi:10.1175/1520-0469(2004)061<0754:RTDOSD>2.0.CO;2.

_ diabatic Rossby vortex: A coherent structure of the moist baroclinic atmosphere. J. Atmos. Sci., 62, 2703-2725, doi:10.1175/JAS3472.1.

Nielsen-Gammon, J. W., and R. J. Lefevre, 1996: Piecewise tendency diagnosis of dynamical processes governing the development of an upper-tropospheric mobile trough. J. Atmos. Sci., 53, 3120-3142, doi:10.1175/1520-0469(1996)053<3120: PTDODP $>2.0 . \mathrm{CO} ; 2$.

NOAA/USDA, 2007: Weekly Weather and Crop Bulletin. Vol. 94, No. 24, 24 pp. [Available online at http://usda.mannlib.cornell. edu/usda/waob/weather_weekly//2000s/2007/weather_weekly10-31-2007.pdf.]

Orlanski, I., and E. K. M. Chang, 1993: Ageostrophic geopotential fluxes in downstream and upstream development of baroclinic waves. J. Atmos. Sci., 50, 212-225, doi:10.1175/ 1520-0469(1993)050<0212:AGFIDA > 2.0.CO;2.

— , and J. P. Sheldon, 1995: Stages in the energetics of baroclinic systems. Tellus, 47A, 605-628, doi:10.1034/ j.1600-0870.1995.00108.x.

Pantillon, F. P., J.-P. Chaboureau, P. J. Mascart, and C. Lac, 2013: Predictability of a Mediterranean tropical-like storm downstream of the extratropical transition of Hurricane Helene (2006). Mon. Wea. Rev., 141, 1943-1962, doi:10.1175/ MWR-D-12-00164.1.

,$- \ldots$, and E. Richard, 2015: Remote impact of North Atlantic hurricanes on the Mediterranean during episodes of intense rainfall in autumn 2012. Quart. J. Roy. Meteor. Soc., 141, 967978, doi:10.1002/qj.2419.

Parker, T. J., G. J. Berry, and M. J. Reeder, 2014: The structure and evolution of heat waves in southeastern Australia. J. Climate, 27, 5768-5785, doi:10.1175/JCLI-D-13-00740.1.

Pfahl, S., E. Madonna, M. Boettcher, H. Joos, and H. Wernli, 2014: Warm conveyor belts in the ERA-Interim dataset (1979-2010). Part II: Moisture origin and relevance for precipitation. J. Climate, 27, 27-40, doi:10.1175/ JCLI-D-13-00223.1.

Quinting, J. F., and S. C. Jones, 2016: On the impact of tropical cyclones on Rossby wave packets: A climatological perspective. Mon. Wea. Rev., 144, 2021-2048, doi:10.1175/ MWR-D-14-00298.1.

Raphael, M. N., 2003: The Santa Ana Winds of California. Earth Interact., 7, doi:10.1175/1087-3562(2003)007<0001: TSAWOC $>2.0 . \mathrm{CO} ; 2$.

Raymond, D. J., and H. Jiang, 1990: A theory for long-lived mesoscale convective systems. J. Atmos. Sci., 47, 3067-3077, doi:10.1175/1520-0469(1990)047<3067:ATFLLM>2.0.CO;2.

Riemer, M., and S. C. Jones, 2010: The downstream impact of tropical cyclones on a developing baroclinic wave in idealized scenarios of extratropical transition. Quart. J. Roy. Meteor. Soc., 136, 617-637, doi:10.1002/qj.605.

,-- , and C. A. Davis, 2008: The impact of extratropical transition on the downstream flow: An idealized modelling study with a straight jet. Quart. J. Roy. Meteor. Soc., 134, 69-91, doi:10.1002/qj.189.

Rivera-Trejo, F., G. Soto-Cortés, and B. Méndez-Antonio, 2010: The 2007 flood in Tabasco, Mexico: An integral analysis of a devastating phenomenon. Int. J. River Basin Manage., 8 , 255-267, doi:10.1080/15715124.2010.508746.

Rodwell, M. J., and Coauthors, 2013: Characteristics of occasional poor medium-range weather forecasts for Europe. Bull. Amer. Meteor. Soc., 94, 1393-1405, doi:10.1175/ BAMS-D-12-00099.1.

Saha, S., and Coauthors, 2010: The NCEP Climate Forecast System Reanalysis. Bull. Amer. Meteor. Soc., 91, 1015-1057, doi:10.1175/2010BAMS3001.1.

Schultz, D. M., W. E. Bracken, L. F. Bosart, G. J. Hakim, M. A. Bedrick, M. J. Dickinson, and K. R. Tyle, 1997: The 1993 Superstorm cold surge: Frontal structure, gap flow, and tropical impact. Mon. Wea. Rev., 125, 5-39, doi:10.1175/ 1520-0493(1997)125<0005:TSCSFS > 2.0.CO;2.

Shapiro, M., and Coauthors, 1999: A planetary-scale to mesoscale perspective of the life cycles of extratropical cyclones: The bridge between theory and observations. The Life Cycles of 
Extratropical Cyclones, M. A. Shapiro and S. Grønås, Eds., Amer. Meteor. Soc., 139-185.

Shapiro, M. A., T. Hampel, and A. J. Krueger, 1987: The Arctic tropopause fold. Mon. Wea. Rev., 115, 444-454, doi:10.1175/ 1520-0493(1987)115<0444:TATF>2.0.CO;2.

Simmons, A. J., and B. J. Hoskins, 1979: The downstream and upstream development of unstable baroclinic waves. J. Atmos. Sci., 36, 1239-1254, doi:10.1175/1520-0469(1979)036<1239: TDAUDO $>2.0 . \mathrm{CO} ; 2$.

Small, I. J., 1995: Santa Ana winds and the fire outbreak of fall 1993. NOAA Tech. Memo. NWS WR-230, 48 pp.

Sodemann, H., and A. Stohl, 2013: Moisture origin and meridional transport in atmospheric rivers and their association with multiple cyclones. Mon. Wea. Rev., 141, 2850-2868, doi:10.1175/MWR-D-12-00256.1.

Sprenger, M., O. Martius, and J. Arnold, 2013: Cold surge episodes over southeastern Brazil-A potential vorticity perspective. Int. J. Climatol., 33, 2758-2767.

Steenburgh, W. J., D. M. Schultz, and B. A. Colle, 1998: The structure and evolution of gap outflow over the Gulf of Tehuantepec, Mexico. Mon. Wea. Rev., 126, 2673-2691, doi:10.1175/1520-0493(1998)126<2673:TSAEOG >2.0.CO;2.

Stein, A. F., R. R. Draxler, G. D. Rolph, B. J. B. Stunder, M. D. Cohen, and F. Ngan, 2015: NOAA's HYSPLIT atmospheric transport and dispersion modeling system. Bull. Amer. Meteor. Soc., 96, 2059-2077, doi:10.1175/BAMS-D-14-00110.1.

Steinschneider, S., and U. Lall, 2015: Daily precipitation and tropical moisture exports across the eastern United States: An application of archetypal analysis to identify spatiotemporal structure. J. Climate, 28, 8585-8602, doi:10.1175/ JCLI-D-15-0340.1.

Stoelinga, M. T., 1996: A potential vorticity-based study of the role of diabatic heating and friction in a numerically simulated baroclinic cyclone. Mon. Wea. Rev., 124, 849-874, doi:10.1175/ 1520-0493(1996)124<0849:APVBSO > 2.0.CO;2.

Thorncroft, C. D., B. J. Hoskins, and M. E. McIntyre, 1993: Two paradigms of baroclinic-wave life-cycle behaviour. Quart. J. Roy. Meteor. Soc., 119, 17-55, doi:10.1002/qj.49711950903.
Thornton, P. E., S. W. Running, and M. A. White, 1997: Generating surfaces of daily meteorological variables over large regions of complex terrain. J. Hydrol., 190, 214-251, doi:10.1016/ S0022-1694(96)03128-9.

Torn, R. D., 2010: Diagnosis of the downstream ridging associated with extratropical transition using short-term ensemble forecasts. J. Atmos. Sci., 67, 817-833, doi:10.1175/ 2009JAS3093.1.

—_, and G. J. Hakim, 2015: Comparison of wave packets associated with extratropical transition and winter cyclones. Mon. Wea. Rev., 143, 1782-1803, doi:10.1175/ MWR-D-14-00006.1.

— J. S. Whitaker, P. Pegion, T. M. Hamill, and G. J. Hakim, 2015: Diagnosis of the source of GFS medium-range track errors in Hurricane Sandy (2012). Mon. Wea. Rev., 143, 132152, doi:10.1175/MWR-D-14-00086.1.

UCAR/NCAR/CISL/TDD, 2016: The NCAR Command Language (version 6.3.0), doi:10.5065/D6WD3XH5.

Wernli, B. H., and H. C. Davies, 1997: A Lagrangian-based analysis of extratropical cyclones. I: The method and some applications. Quart. J. Roy. Meteor. Soc., 123, 467-489, doi:10.1002/ qj. 49712353811.

Wernli, H., and M. Sprenger, 2007: Identification and ERA-15 climatology of potential vorticity streamers and cutoffs near the extratropical tropopause. J. Atmos. Sci., 64, 1569-1586, doi:10.1175/JAS3912.1.

Westerling, A. L., D. R. Cayan, T. J. Brown, B. L. Hall, and L. G. Riddle, 2004: Climate, Santa Ana winds and autumn wildfires in Southern California. Eos, Trans. Amer. Geophys. Union, 85, 289-296, doi:10.1029/2004EO310001.

Wiegand, L., A. Twitchett, C. Schwierz, and P. Knippertz, 2011: Heavy precipitation at the Alpine south side and Saharan dust over central Europe: A predictability study using TIGGE. Wea. Forecasting, 26, 957-974, doi:10.1175/ WAF-D-10-05060.1.

Winters, A. C., and J. E. Martin, 2014: The role of a polar/subtropical jet superposition in the May 2010 Nashville flood. Wea. Forecasting, 29, 954-974, doi:10.1175/WAF-D-13-00124.1. 